\title{
The Development of Codas in Catalan*
}

\author{
Pilar Prieto \\ ICREA-UAB \\ Universitat Autònoma de Barcelona. Departament de Filologia Catalana \\ 08193 Bellaterra (Barcelona). Spain \\ pilar.prieto@uab.es
}

\section{Marta Bosch-Baliarda}

Universitat Autònoma de Barcelona. Departament de Filologia Catalana 08193 Bellaterra (Barcelona). Spain

marta.bosch@uab.es

\begin{abstract}
This paper focuses on the development of syllable-final consonants in Catalan. Developmental data by four Catalan-speaking children (Serra-Solé corpus in CHILDES) has revealed that codas appear with the very first word productions. The role of the following factors in the development of coda acquisition has been systematically analyzed: within-word position, stress, morphological import and segmental composition. The paper presents empirical evidence in favor of the privileged status of metrically prominent syllables (or heads and edges of feet) in licensing coda consonants in Catalan: it is clear that stressed syllables make their coda available before unstressed syllables, independently of within-word position or morphological import. Similarly, word-final positions are privileged and codas in word-final position are acquired earlier than those in wordmedial position. Our results also contribute to the discussion about the potential facilitating effect of morphology in phonological acquisition. While Freitas, Miguel \& Hub Faria (2001) find evidence for an early emergence of plural markers (expressed as word-final coda fricative [- $\left.\int\right]$ ) in European Portuguese, Lleó (2003) reports late acquisition of plural markers (word-final coda fricative $[-\mathrm{s}])$ in Spanish. The Catalan data, like the Spanish data, show that morphological codas are acquired relatively late.
\end{abstract}

Key words: Catalan, phonological acquisition, syllable structure acquisition, coda acquisition.

* Parts of this work were presented at the Xth International Congress for the Study of Child Language (Prieto, Bosch-Baliarda \& Saceda-Ulloa 2005, Berlin, July 2005). We are indebted to the audience at the Berlin meeting for very useful feedback, especially to Katherine Demuth, Maria João Freitas, Sónia Frota, Yvan Rose, and Marina Vigário. We thank the editors of this special issue, especially Conxita Lleó, and two anonymous reviewers, for their detailed comments on an earlier version of the paper. We are particularly indebted to Miquel Serra and Rosa Solé for generously sharing the Serra-Solé Catalan database in CHILDES and granting us access to the video files. Finally, we would like to thank Carla Amado for phonetically transcribing the child Pep. This research has been funded by grants 2002XT-00032 to both authors, grants 2001SGR 00150 from the Generalitat de Catalunya and BFF2003-06590 and BFF2003-09453-C02-C02 from the Ministry of Science and Technology of Spain to the first author and grant CICYT BS 02003-04614 from the Ministry of Science and Technology of Spain to the second author. 


\section{Table of Contents}

1. Introduction

2. Codas in Catalan

3. Database and methodology

4. Coda development in Catalan:

four case studies
5. Conclusion

References

\section{Introduction}

It is generally accepted that the first stage in syllable structure development is the production of simple consonant-vowel (CV) syllables. The CV syllable is thought to be the universally unmarked syllable structure that is present in the children's productions from the onset of speech, independently of the trigger language (e.g. Fikkert 1994, Demuth \& Fee 1995, Fee 1995, Pater 1997). Further complex syllable structures (with codas, complex codas and complex onsets) characterize later developmental stages. The literature on syllable acquisition has pointed out that syllabic development varies significantly across languages and is affected by a variety of factors such as the following (see Fikkert 1994, Lleó, Kuchenbrandt, Kehoe \& Trujillo 2003, and Levelt et al. 1999/2000):

- Stress. Stressed syllables are prominent prosodic units that typically «protect» phonological information: stressed syllables inhibit processes of segmental deletion or reduction, while unstressed syllables frequently allow these processes to apply. Similarly, the psycholinguistic literature shows that stressed syllables facilitate language processing (Seguí et al. 1990). Thus it is expected that the high perceptibility of stressed syllables will facilitate early coda acquisition. Indeed, there is crosslinguistic evidence that codas in stressed/accented syllables are produced before codas in unstressed syllables (Lleó 2003 for Spanish, Freitas, Miguel \& Hub Faria 2001 for European Portuguese, Ota 2003 for Japanese).

- Within-word position. While some crosslinguistic studies report that wordfinal consonants are produced before medial consonants (Rose 2000 for French; Goad \& Brannen 2000 for English), others report that medial codas are acquired before final codas (Lleó 2003 for Spanish; Freitas, Miguel \& Hub Faria 2001 for European Portuguese). This contrast might be attributed to differences in unmarked stress location in these languages: while French systematically places primary stress in the word-final syllable (and in English there is a huge number of stressed monosyllables), in Spanish and Portuguese the general stress pattern is trochaic. In order to tease out the word positional effect on the acquisition of codas, the effect of within-word position will be analyzed in combination with the stress factor.

- Morphological content. It has been contended that morphological information can speed up coda acquisition. Freitas, Miguel \& Hub Faria (2001) report that in Portuguese fricative codas, especially [J], are acquired early in word- 
final position because of their morphological import and despite the fact that they appear in unstressed position (plural marking in NPs and verb endings in VPs). These authors contend that morphosyntactic information plays a crucial role in prosodic development and can facilitate the emergence of a prosodic structure earlier than one would expect to occur based on purely prosodic factors. However, not all data point in the same direction: Lleó (2003, this volume) shows that in Spanish the plural marker, expressed as a word-final fricative coda $-s$, is acquired quite late because it belongs to an unstressed syllable.

- Segmental content. The order of emergence of segments seems to be largely guided by language-specific constraints, as we find clear contrasts across languages. For example, Fikkert (1994) reports that, in the acquisition of Dutch, obstruents are acquired earlier than sonorants and, among the obstruents, plosives are acquired earlier than fricatives. Similarly, in European Portuguese obstruents (coda fricatives) are acquired before sonorants (syllable final liquids) according Freitas, Miguel \& Hub Faria 2001, and Freitas 2001. However, in Peninsular Spanish sonorant coda consonants are acquired before obstruents (Lleó 2003) ${ }^{1}$.

- Frequency. Exposure to a high frequency of coda consonants and complex rhymes in a given language favors early coda acquisition. For example, while in English and German codas appear at the initial stage of word production (see Bernhardt \& Stemberger 1998 for English; Grijzenhout \& Joppen 1998, and Lleó, Kuchenbrandt, Kehoe \& Trujillo 2003 for German), children acquiring languages with a low frequency of codas in the input such as Japanese or Spanish are reported to start producing codas at later developmental stages (Ota 2003 for Japanese, and Lleó 2003 for Spanish). Similarly, Levelt, Schilller \& Levelt's (2000) study of Dutch-speaking children's development of syllable structure show that the syllable shapes that are highest in frequency are acquired first, and the syllable shapes that are lowest in frequency are acquired last. Other work on the acquisition of word-initial consonants has also suggested that crosslinguistic differences in the rate of acquisition may be due to language specific frequencies (Pye, Ingram \& List 1987).

The purpose of this investigation is to examine the acquisition of syllablefinal consonants in Catalan and to clarify the role of the abovementioned factors -namely, stress, within-word position, minimality effects, morphological import and segmental content- in the development of syllable structure. To circumvent the methodological problem of the interaction between factors, we will pay special attention to separating the effect of different conditions. One of the main aims of this article is to determine whether early coda production is guided by crosslinguistic restrictions of markedness (stress, word-finality, minimality) or rather that language-specific statistical properties of the input play an important

1. For Spanish, Lleó (2003:279) reports that the majority of first acquired codas are liquids and nasals appearing in word-medial position. 
role in shaping children's early syllables. Catalan provides a good test case for exploring this issue.

The empirical basis of this investigation consists of a longitudinal analysis of four Catalan-speaking children (Gisela ages $1 ; 8.3$ to $2 ; 8$; Guillem ages $1 ; 1.29$ to $3 ; 0$; Laura ages $1 ; 10.22$ to $3 ; 0.2$; Pep ages $1 ; 1.28$ to $2 ; 5.4)$. This data set corresponds to the Serra-Solé Catalan corpus in the CHILDES website. Systematic longitudinal recordings of these four children were collected and transcribed by a team under the direction of Miquel Serra and Rosa Solé in the 1990s.

The article is organized as follows. Section 2 briefly describes the main features of Catalan syllable structure. Section 3 describes the methodology used to elicit and code the data. Section 4 analyzes the production of codas by the four Catalan children in the Serra-Solé corpus, taking into account the effect of: (a) stress; (b) minimality effects; (c) within-word position; (d) morphological import; (e) segmental factors. Potential interactions between factors are discussed in the relevant sections. Three main conclusions are drawn from the analysis concerning the crucial effect of stress in coda development, the weaker (but significant) effect of word finality, and the lack of importance of morphological information in acquiring coda consonants. The developmental data studied in this article provides strong evidence in favor of the idea that children's linguistic structures reflect the predominant (high frequency) structures in the language being learned.

\section{Codas in Catalan}

Catalan syllable structure is relatively complex with respect to coda structure. The examples in (1) present a typology of the possible syllable structure types found in the language. First, Catalan allows a maximum of two consonants in the onset (see examples in line 3) and a maximum of three consonants in the coda (see last column). By far the most common syllable structure type in the language is $\mathrm{CV}$, and then CVC, and the presence of more than one consonant in syllable-final position can be considered quite infrequent. Even though the most common consonants in the coda are alveolar (namely, the nasal [n], the fricative [s], the rhotic [r] and the lateral [1]), other consonants are also possible (especially, in word-final position), namely, plosives [p, t, $\mathrm{k}, \mathrm{b}, \mathrm{d}, \mathrm{g}]$, fricatives $\left[\mathrm{f}, \int, 3\right]$, affricates $[\widehat{\mathrm{d}}, \mathrm{t}]$ ], nasals $[\mathrm{m}, \mathrm{n}]$, laterals $[\kappa]$, and glides $[\mathrm{j}, \mathrm{w}] .^{2}$

2. In both Catalan and Spanish, postvocalic glides are generally classified as part of the coda (escaire [əs'kajrə] 'edge', eina ['cjnə] 'tool', brau ['braw] 'bull', cuina ['kujnə] 'kitchen'). Arguments in favor of this structure are the following: (a) the fact that glides in this position display a phonological behavior that is similar to codas; (b) the fact that antepenultimate stress is impossible if the penult contains a branching rhyme and this also occurs when the postvocalic segment is a glide; (b) the existence of segmental processes which replace codas such as liquids $r$ and $l$ with glides in certain Caribbean Spanish dialects (see Harris 1983 for Spanish; Bonet \& Lloret 1998:63 for Catalan). 


\begin{tabular}{|c|c|c|c|}
\hline$\underline{\text { No coda }}$ & $\underline{\text { Simple coda }}$ & Complex coda $(2 \mathrm{C})$ & Complex coda $(3 \mathrm{C})$ \\
\hline$u[\mathrm{u}]$ & ham ['am] & $\operatorname{art}$ ['art] & erms ['erms] \\
\hline 'one' & 'fish hook' & 'art' & 'uncultivated.mpl' \\
\hline$b o$ ['bo] & sol ['sol] & part ['part] & text ['tekst] \\
\hline 'good.ms' & 'sun' & 'part' & 'text' \\
\hline tro ['tro] & tren ['tren] & trens ['trens] & bruscs ['brusks] \\
\hline 'thunder' & 'train' & 'trains' & 'abrupt.mpl' \\
\hline
\end{tabular}

The degree of complexity that codas can adopt depends on their position within the word. While in word-medial position, codas have a maximum of two segments (e.g., perspicaç [pərspi'kas] 'shrewd', abstenció [əpstən'sjo] 'abstention', exposició [əkspuzi'sjo] 'exhibition', institut [institut] 'institution', circumscripció [sirkumskrip'sjo] 'circumscription', Eustaqui [əws'taki] 'Eustace', obstacle [upstakklə] 'obstacle'), word-final positions allow combinations of up to three consonants (dorms ['dorms] 'you sleep', salms ['salms] 'psalms', arcs ['arks] 'archways', corbs ['korps] 'ravens', asteriscs [əstว'risks] 'asterisks', golfs ['golfs] 'gulfs', text ['tekst] 'text').

Because of the inflectional nature of the language, some word-final codas in Catalan convey grammatical information such as number and gender for nouns, and tense, aspect, person for verbs. In Catalan, word-final $-s$ marks plural in nouns (casa ['kazə] 'house' vs. cases ['kazəs] 'houses') and person-number in verbs (canta ['kantə] 'I sing' vs. cantes ['kantə] 'you sing'). In verbal forms, personnumber categories are signalled, among other forms, by word-final $-m,-w$, and - $n$ (cantem [kən'tem] 'we sing', canteu [kəñ'tew] 'you.pl sing', canten ['kantən] 'they sing').

In order to assess the relative frequency of codas in relation to stress and within-word position in Catalan, we performed an analysis of the distribution of closed syllables based on the speech of the four children in the Serra-Sole corpus in CHILDES. Each target closed syllable was manually codified by the second author in relation to stress status (stressed vs. unstressed) and within-word position (wordfinal vs. word-medial). Codifications were based on 'target' syllables that the children were attempting to produce, not actual productions. Table 1 summarizes the data used for the frequency study, including information about the age range and the files and number of words analyzed for each child.

Table 1. Data used in the distributional analysis.

\begin{tabular}{lllll}
\hline Name & N of sessions & N of closed syllables & Age Range & Corpus \\
\hline Gisela & 12 & 576 & $1 ; 8.3-2 ; 8$ & Serra-Solé (CHILDES) \\
Guillem & 15 & 837 & $1 ; 1.29-2 ; 8$ & Serra-Solé (CHILDES) \\
Laura & 12 & 1126 & $1 ; 7.20-2 ; 8$ & Serra-Solé (CHILDES) \\
Pep & 13 & 1344 & $1 ; 1.28-2 ; 8$ & Serra-Solé (CHILDES) \\
\hline
\end{tabular}


Frequency of stressed vs. unstressed codas

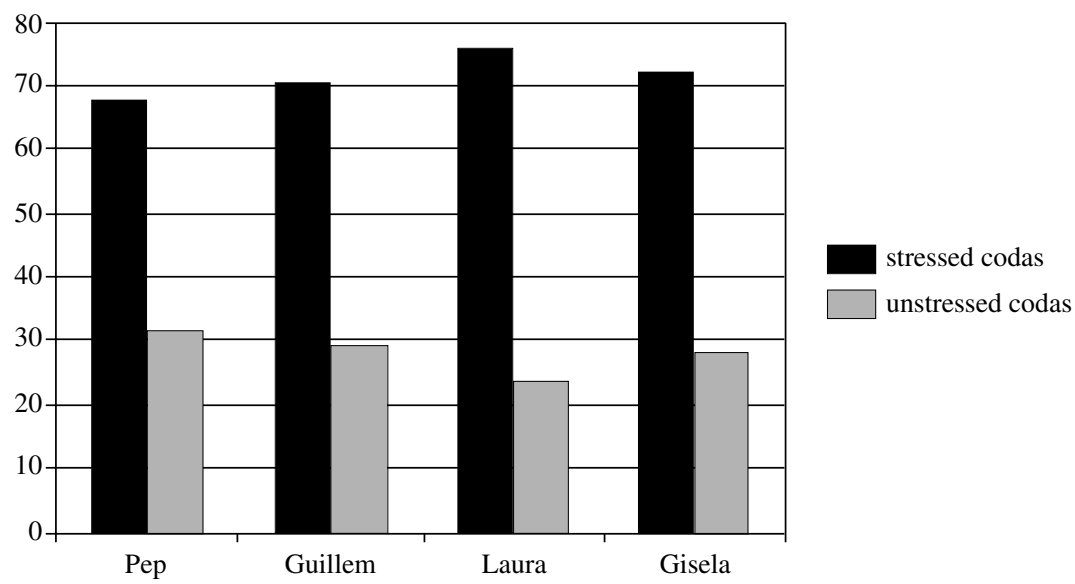

Figure 1. Percentage of target codas in stressed syllables (in black) and in unstressed syllables (in light grey) for the 4 children under study (Pep, Guillem, Laura, and Gisela).

Frequency of stressed codas in final and medial position

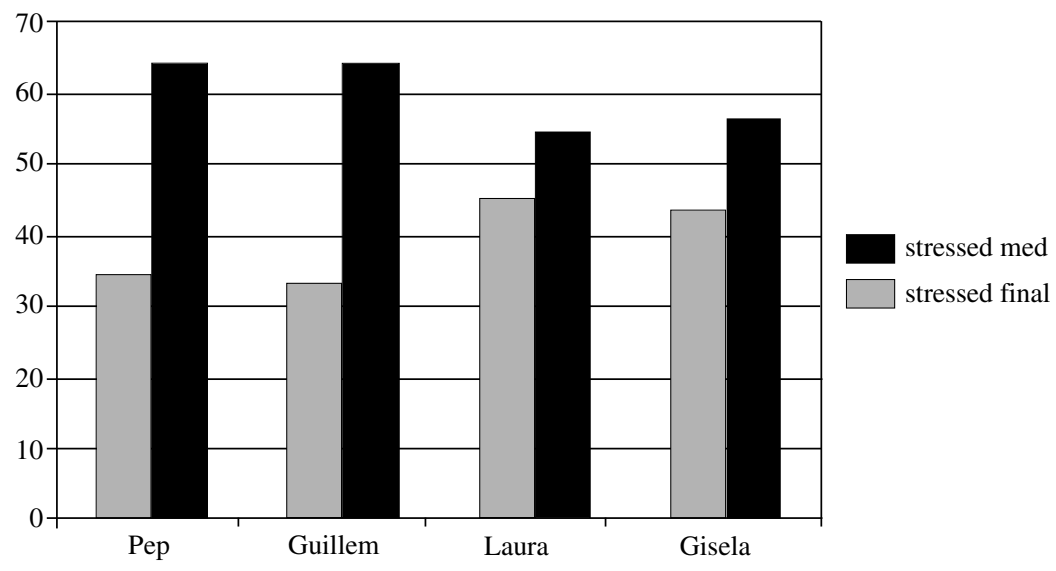

Figure 2. Percentage of target stressed codas in word-final (in black) and in word-medial position (in light grey) for the 4 children under study (Pep, Guillem, Laura, and Gisela).

Figure 1 plots the percentage of target codas in stressed syllables (in black) vs. the percentage of target codas in unstressed syllables (in light grey) for the 4 children under study (Pep, Guillem, Laura, and Gisela). The four children show the same pattern. Clearly, Catalan has more stressed codas than unstressed codas (a mean percentage of $71.69 \%$ vs. $28.29 \%$ respectively). 
Figure 2 plots the percentage of target codas in stressed syllables in word-final (in black) and in word-medial position (in light grey) for the 4 children. The data shows a consistent pattern for the 4 children, namely, more stressed codas in wordfinal position than in word-medial position (with a mean percentage of $60.07 \%$ vs. $39.41 \%$ respectively).

Given the frequency findings for Catalan, it is predicted that Catalan-speaking children will acquire codas in stressed positions earlier than codas in unstressed positions. Similarly, a timing difference is also predicted for the acquisition of word-final vs. word-medial consonants.

\section{Database and methodology}

The database for this study comprises a series of longitudinal recordings of four Catalan-speaking children, Gisela, Guillem, Laura, and Pep. As mentioned above, they come from the Serra-Sole corpus on Catalan available in the CHILDES site (MacWhinney \& Snow 1985). The children were selected because in all cases both parents used Central Catalan almost exclusively in the family life (they all are from Barcelona). They had varying degrees of contact with Spanish. The children were selected because both parents used Central Catalan almost exclusively in their family context (they all are from Barcelona). However, they had slightly different degrees of contact with Spanish. While Gisela and Laura had Catalan as the exclusive language of the family setting and also in relation to babysitters, Guillem and Pep each had a Spanish babysitter in the early stages (Pep at 1;0 and Guillem at $0 ; 1)$. With respect to their contact with Spanish, Pep could actually be considered the child with most contact with Spanish, since his Spanish babysitter took care of him until he went to school (at 2;8). On the other hand, Guillem had two Catalan babysitters after the first year of age. Finally, Laura, Gisela, and Guillem had more regular contact with Spanish after starting day care (Guillem at 1;0, Gisela at approximately $1 ; 1$ and Laura at $1 ; 2$ ).

Each child was video-taped on a monthly basis starting from the 25-word period (between $1 ; 1$ and $1 ; 8$, depending on the child) up until four years of age. Data was collected following a naturalistic design, that is, spontaneous situations were recorded at home with the mother and the researcher. After recording, the data was transcribed in semiorthographic form by a team directed by Miquel Serra and Rosa Solé. Each child's output was transcribed by a main transcriber: if the transcriber had transcription doubts, he or she asked three different judges, and, if no consensus was reached, the sequence was considered unintelligible («XX»). A second transcription round was assigned to another transcriber, who followed the same guidelines. The transcription was done in orthographic form and, when the output was phonologically simplified, another level of semiorthographic form (marked with \%) was used to codify phenomena such as syllable or coda omissions, and segmental substitutions.

Table 2 presents a summary of the data used for the longitudinal study, including information about the age range and the files and number of words analyzed for each child. The database for this study comprises the children's utterances from the 
Table 2. Data used in the study.

\begin{tabular}{lllll}
\hline Name & N of sessions & N of words & Age Range & Corpus \\
\hline Gisela & 10 & 412 & $1 ; 8.3-2 ; 8$ & Serra-Solé (CHILDES) \\
Guillem & 25 & 848 & $1 ; 1.29-3 ; 0$ & Serra-Solé (CHILDES) \\
Laura & 13 & 1031 & $1 ; 7.20-3 ; 0.2$ & Serra-Solé (CHILDES) \\
Pep & 16 & 1035 & $1 ; 1.28-2 ; 5.4$ & Serra-Solé (CHILDES) \\
\hline
\end{tabular}

time point at which the children tried to produce target words containing codas up until the time when the acquisition of codas was practically finalized. This is why the age ranges analyzed are not the same for each child. The number of codified words correspond to words which contained at least one closed syllable, as open syllables were not included in the analysis. Note that three of the children produce more codas than the number of words they produce (compare Tables 1 and 2). This is because some of the tokens in the corpus contain both medial and word-final codas.

Only spontaneous utterances were taken into account, and children's repetitions of the adult form were discarded. Even though access to the actual recordings was granted to us, the data was gathered from the semiorthographic transcription provided by the Serra-Solé database. Target closed syllables were codified by the second author according to whether the coda position was present or not in the child's production, without taking into account the accuracy of coda production $(\mathrm{C}=$ Coda vs. $\mathrm{nC}=$ No Coda, see Table 2$)$. Thus substituted segments and glides were included in the category of produced codas. Data from definite articles and protoarticles were also included in the analysis (and considered to be unstressed pretonic syllables within the prosodic word domain).

Each target closed syllable was codified in an Excel database according to the following 10 parameters, appearing on the first line of Table 3: (1) session and age of the child; (2) whether the coda was simple (S) or complex (C); (3) whether the coda was a morphological (M) or non-morphological coda (nM); (4) the type of segment, codified with place and manner of articulation; (5) whether the coda belonged to a target syllable that is stressed (T) or unstressed (A); (6) the position of the coda within the word, be it word-final (F) or word-medial (M); (7) whether

Table 3. Codification of the parameters used in the study.

\begin{tabular}{|c|c|c|c|c|c|c|c|c|c|}
\hline $\begin{array}{l}1 \\
\text { Session }\end{array}$ & $\begin{array}{l}2 \\
\text { Coda } \\
\text { S/C }\end{array}$ & $\begin{array}{l}3 \\
\text { Morf / } \\
\text { NoMorf }\end{array}$ & $\begin{array}{l}4 \\
\text { Segmental } \\
\text { coding }\end{array}$ & $\begin{array}{l}\mathbf{5} \\
\text { Stress } \\
\text { T/A }\end{array}$ & $\begin{array}{l}6 \\
\text { Position } \\
\text { F / M }\end{array}$ & $\begin{array}{l}7 \\
\text { Monosyl/ } \\
\text { Polysyl }\end{array}$ & $\begin{array}{l}8 \\
\text { Adult form > } \\
\text { child form }\end{array}$ & $\begin{array}{l}9 \\
\mathrm{~N}\end{array}$ & $\begin{array}{l}10 \\
\mathrm{nC} / \\
\mathrm{C}\end{array}$ \\
\hline $01-09 / 1 ; 1.28$ & S & M & Lat Cor & A & $\mathrm{F}$ & M & $\mathrm{el}>\mathrm{a}$ & 3 & $\mathrm{nC}$ \\
\hline $01-09 / 1 ; 1.28$ & S & $\mathrm{nM}$ & Ocl Cor & A & M & $\mathrm{P}$ & petitsuis $>$ ti & 5 & $\mathrm{nC}$ \\
\hline $01-09 / 1 ; 1.28$ & S & $\mathrm{nM}$ & Fric Cor & $\mathrm{T}$ & M & $\mathrm{P}$ & aquesta $>$ queta & 6 & $\mathrm{nC}$ \\
\hline $01-09 / 1 ; 1.28$ & S & $\mathrm{nM}$ & Glid Vel & $\mathrm{T}$ & M & $\mathrm{P}$ & aigua $>$ aba & 1 & $\mathrm{nC}$ \\
\hline $01-09 / 1 ; 1.28$ & $\mathrm{~S}$ & $\mathrm{nM}$ & Ocl Cor & A & M & $\mathrm{P}$ & petitsuis $>$ tit & 1 & $\mathrm{C}$ \\
\hline
\end{tabular}


the word that contained the coda was monosyllabic $(\mathrm{M})$ or polysyllabic $(\mathrm{P}) ;(8)$ the adult and the child form; (9) number of exact items in the same session; (10) whether the coda was phonetically realized or not $(\mathrm{C}=\mathrm{Coda} / \mathrm{nC}=$ No Coda). Table 3 shows the first lines of the Excel file produced for the child Pep.

\section{Coda development in Catalan: four case studies}

\subsection{The emergence of codas}

Even though it is generally claimed that an initial stage without codas tends to be a universal stage for all children, recent studies with English- and German-speaking children report that codas are present in initial periods of word production (see Bernhardt \& Stemberger 1998 for English and Grijzenhout \& Joppen 1998 for German). The fast development of codas in English or German, especially that of final codas, has been attributed to the high frequency of codas in the target languages (see Lleó, Kuchenbrandt, Kehoe \& Trujillo 2003). By contrast, languages with relatively low frequency of codas such as Japanese or Spanish delay the timing of coda development. Japanese children acquire simplex codas quite late (at around $1 ; 10$ or 1;11) in comparison to English-speaking children, who acquired codas before 1;8 (Ota 2003). Similarly, Lleó, Kuchenbrandt, Kehoe \& Trujillo (2003) report that two of the three Spanish children under study produced almost no codas until about 2 years of age: the percentage of final codas produced by José at 2;2 reached only $15 \%$ and that of María amounted to only 5\% at 2;2, with one single token, and finally $21 \%$ at 2;3. Yet the other child, Miguel, showed higher percentages of coda production, which reached $70 \%$ at $1 ; 7$.

The Catalan-speaking children began producing target CVC syllables very early, many of them from their very first attemps to produce target codas. In (2) we list illustrative examples of the Catalan children's coda productions in the initial stages of word production. For example, Guillem consistently produced his name as ['cm] instead of [gi' $K \mathrm{Em}]$ at 1;4. Typically, CVC monosyllables (one of the most common word-types produced at the time) were targeted as CVC, even though it was also sometimes truncated to CV outputs: see for example the production of llum ['Kum] as [bu:] and [bum] by Laura in the same session. [NB: throughout the paper, stressed syllables will be underlined in the orthographic form.]

(2) Production of target CVC syllables in first stages of coda development

\begin{tabular}{|c|c|c|c|c|}
\hline Orth. form & $\underline{\text { Adult form }}$ & Child form & $\underline{\text { Gloss }}$ & Child \\
\hline Guillem & [gi'Kcm] & ['cm] & 'William' & Guillem $1 ; 4.26$ \\
\hline nyam & ['nam] & ['am] & 'to eat' & Guillem $1 ; 4.26$ \\
\hline$\underline{t o c}, \underline{t o c}$ & ['tok 'tok] & ['tok'tok] & 'knock knock' & Pep 1;0.26 \\
\hline petit & [pr'tit] & [patit] & 'small' & Pep $1 ; 1.24$ \\
\hline$\underline{\mathrm{meu}}$ & ['mew] & ['mew] & 'mine' & Pep $1 ; 2.3$ \\
\hline$\underline{P o l}$ & ['pol] & ['pol] & 'Paul' & Pep $1 ; 4.23$ \\
\hline aquest & ['ket] & ['ket] & 'this.ms' & Pep $1 ; 5.28$ \\
\hline llum & ['Kum] & ['bu:],['bum] & 'light' & Laura 1:7.20 \\
\hline
\end{tabular}


The following table 4 provide information about coda production in each session for the 4 children. The second column shows the number of target closed syllables (in raw numbers) and the third column the percentage of codas actually produced by the children in each session. The total number of codas targetted is 896 (Guillem), 1,034 (Pep), 411 (Gisela) and 1,030 (Pep).

Catalan provides an interesting basis of comparison with the acquisition of codas in other languages. Codas in Catalan are acquired slightly later compared to English or German and relatively early compared to Spanish or Japanese. As is well known, English, and to some extent German, are languages with a great number of monosyllables: this single syllable, generally containing a coda, might be acting as an attractor for early coda production. Figure 3 shows the distribution in tokens of prosodic word shapes of content words in Catalan, English and Spanish. Data come from an analysis of child-directed speech (Prieto 2006 for Catalan, Roark \& Demuth 2000 for English and Saceda-Ulloa 2005 for Spanish). The Catalan and Spanish data are directly comparable, as only stressed lexical items were included in the analysis (e.g. nouns, verbs, adjectives, adverbs), leaving out a few closedclass words with very high-frequency tokens. On the other hand, Roark \& Demuth's (2000) counts are not directly comparable with the Romance data, as these materials included grammatical function items in the monosyllabic forms, thus inflating

Frequency of prosodic word shapes in English, Catalan and Spanish

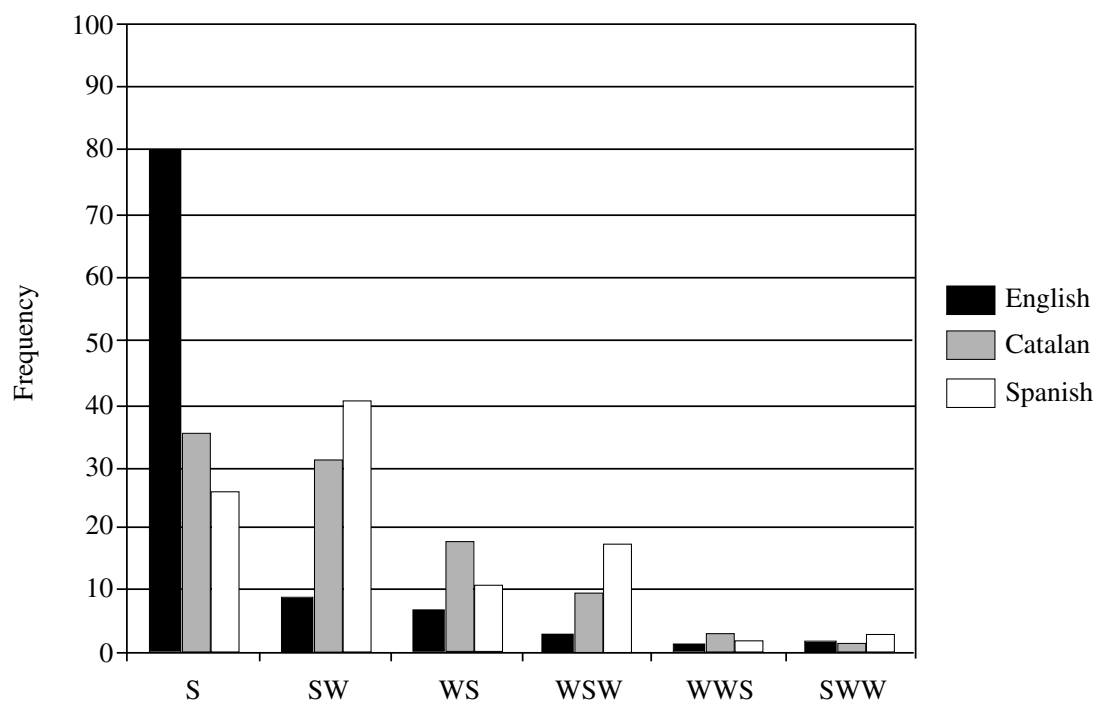

Figure 3. Distribution of prosodic word shapes in Catalan, English and Spanish childdirected speech (data from English is taken from Roark \& Demuth 2000 and Spanish data from Saceda-Ulloa 2005). 
Table 4. Number of target codas and percentage of codas produced in each session for the 4 children.

\begin{tabular}{|c|c|c|c|c|c|}
\hline Guillem & $\mathrm{N}$ target codas & $\begin{array}{l}\% \text { of target } \\
\text { codas produced }\end{array}$ & Pep & $\mathrm{N}$ target codas & $\begin{array}{l}\% \text { of target } \\
\text { codas produced }\end{array}$ \\
\hline $1 ; 1.29$ & 1 & $0 \%$ & $1 ; 1.28$ & 6 & $33 \%$ \\
\hline $1 ; 4.26$ & 19 & $50 \%$ & $1 ; 2.3$ & 10 & $80 \%$ \\
\hline $1 ; 7.15$ & 4 & $80 \%$ & $1 ; 3.23$ & 13 & $77 \%$ \\
\hline $1 ; 8$ & 5 & $33 \%$ & $1 ; 4.24$ & 16 & $94 \%$ \\
\hline $1 ; 9.12$ & 13 & $58 \%$ & $1 ; 5.29$ & 33 & $75 \%$ \\
\hline $1 ; 9.24$ & 20 & $67 \%$ & $1 ; 6.23$ & 22 & $59 \%$ \\
\hline $1 ; 11.13$ & 12 & $63 \%$ & $1 ; 8$ & 19 & $100 \%$ \\
\hline $2 ; 0.12$ & 17 & $73 \%$ & $1 ; 8.30$ & 16 & $81 \%$ \\
\hline $2 ; 1.14$ & 36 & $62 \%$ & $1 ; 10.6$ & 110 & $79 \%$ \\
\hline $2 ; 2.11$ & 36 & $68 \%$ & $1 ; 11.6$ & 54 & $87 \%$ \\
\hline $2 ; 2.28$ & 58 & $69 \%$ & $2 ; 0$ & 42 & $98 \%$ \\
\hline $2 ; 3.12$ & 63 & $73 \%$ & $2 ; 1.1$ & 98 & $98 \%$ \\
\hline $2 ; 3.18$ & 43 & $58 \%$ & $2 ; 2.3$ & 117 & $94 \%$ \\
\hline $2 ; 4.24$ & 30 & $64, \%$ & $2 ; 3.10$ & 185 & $93 \%$ \\
\hline $2 ; 5.25$ & 42 & $68 \%$ & $2 ; 4.4$ & 100 & $95 \%$ \\
\hline $2 ; 5.29$ & 20 & $63 \%$ & $2 ; 5.4$ & 193 & $99 \%$ \\
\hline $2 ; 6.10$ & 49 & $73 \%$ & & & \\
\hline $2 ; 7.9$ & 44 & $72 \%$ & & & \\
\hline $2 ; 7.25$ & 41 & $60 \%$ & & & \\
\hline $2 ; 9.8$ & 24 & $72 \%$ & & & \\
\hline $2 ; 10.3$ & 51 & $79 \%$ & & & \\
\hline $2 ; 11.5$ & 67 & $86 \%$ & & & \\
\hline $2 ; 11.21$ & 51 & $95 \%$ & & & \\
\hline $2 ; 11.25$ & 94 & $93 \%$ & & & \\
\hline $3 ; 0$ & 7 & $100 \%$ & & & \\
\hline Gisela & $\mathrm{N}$ target codas & $\begin{array}{l}\% \text { of target } \\
\text { codas produced }\end{array}$ & Laura & $\mathrm{N}$ target codas & $\begin{array}{l}\% \text { of target } \\
\text { codas produced }\end{array}$ \\
\hline $1 ; 8.3$ & 7 & $57 \%$ & $1 ; 7.20$ & 14 & $71 \%$ \\
\hline $1 ; 8.24$ & 14 & $71 \%$ & $1 ; 9.7$ & 24 & $92 \%$ \\
\hline $1 ; 9$ & 7 & $57 \%$ & $1 ; 10.22$ & 24 & $75 \%$ \\
\hline $1 ; 10.7$ & 19 & $63 \%$ & $1 ; 11.12$ & 55 & $80 \%$ \\
\hline $1 ; 11.11$ & 15 & $73 \%$ & $2 ; 2.5$ & 45 & $66 \%$ \\
\hline $2 ; 1.23$ & 11 & $82 \%$ & $2 ; 2.13$ & 33 & $81 \%$ \\
\hline $2 ; 2.6$ & 46 & $79 \%$ & $2 ; 4.11$ & 41 & $85 \%$ \\
\hline $2 ; 4.25$ & 76 & $87 \%$ & $2 ; 5.8$ & 123 & $81 \%$ \\
\hline $2 ; 6.23$ & 32 & $88 \%$ & $2 ; 6.25$ & 64 & $80 \%$ \\
\hline \multirow[t]{4}{*}{$2 ; 8$} & 184 & $85 \%$ & $2 ; 7.20$ & 132 & $90 \%$ \\
\hline & & & $2 ; 8.30$ & 121 & $96 \%$ \\
\hline & & & $2 ; 11.17$ & 154 & $85 \%$ \\
\hline & & & $3 ; 0.2$ & 200 & $93 \%$ \\
\hline
\end{tabular}


the monosyllabic counts and depressing all others. The graph shows that while English has 80\% monosyllables and Catalan around 56\%, Spanish has much less (around 25\%).

In Catalan, the majority of stressed monosyllables are made up of a closed syllable (around 63\% are of the CVC type and 37\% of the CV type). We thus hypothesize that the early appearance of codas in Catalan when compared to Spanish is due to the following characteristics of this language: (1) a higher frequency of monosyllables with coda consonants; (2) a higher frequency of complex codas in wordfinal position (see section 2).

\subsection{Effects of stress}

Recent research has been driven by the observation that prosodically strong positions typically allow greater prosodic complexity: thus it is expected that the high perceptibility and prominence of stressed syllables will facilitate the acquisition of codas in early word production, and that codas in stressed syllables will be acquired earlier than codas in unstressed positions. This has been found to be true for languages such as Spanish (Lleó 2003) and European Portuguese (Freitas, Miguel \& Hub Faria 2001). As the examples in (3) show, codas tend to appear in stressed positions before unstressed positions in a given word (cargol [ə่)l] 'snail', timbal [tibal] 'drums'). Even though at first sight we might think that coda realization has to do with segmental complexity (that is, consonants that are harder to produce will not be phonetically realized), we can also observe near-minimal contrasts whereby the child produces the consonant in stressed position and does not produce it in unstressed position. For example, Gisela produces the word pantalons 'trousers' as [pətว'lon], where she crucially deletes the nasal in the initial unstressed syllable (Gisela 2;4.25). Similarly, we can report the contrast between ànec ['ana] 'duck' (with deletion of the word-final obstruent) and porquet [pu'ket] 'piglet' (with realization of the same consonant) in the same session (Laura $2 ; 11.17)$.

(3) Examples of coda production in stressed syllables

\begin{tabular}{|c|c|c|c|c|}
\hline rth. form & Adult form & Child form & Sloss & Child \\
\hline cargol & {$[\mathrm{k} \partial$} & โด่าไ & 'sna & fui \\
\hline timbal & & & 'dr & \\
\hline perdut & & & 'los & \\
\hline formatget & $\left.1{ }^{3} \varepsilon t\right]$ & & 1 cheese' & \\
\hline sortit & & & & Pep \\
\hline dormint & [du & & & Pep $1 ; 10.6$ \\
\hline pantalon & [pən tə'lons] & ə'lons] & 'trousers' & Gisela $2 ; 4.25$ \\
\hline
\end{tabular}

The four graphs in Figure 4 show the percentages of coda production as a function of the stress factor, that is, whether the coda belongs to a stressed syllable (continuous lines) or to an unstressed syllable (dashed lines), for the 4 chil- 
dren. As all the figures in this article, the percentages indicate the ratio of phonetically produced codas out of total number of target codas in the relevant condition. The information in the graphs is presented on a session-by-session basis. Only exceptionally, when the number of cases per session was very small, are two sessions merged into one data point. Although there is individual variation in the percentages of coda deletion and the age when the production of codas reaches a $100 \%$ value (compare for example Guillem and Laura, who achieve 100\% correct production around three years of age vs. Pep, who achieves $100 \%$ correct production at 2;5), the four children clearly show an improved performance in the production of stressed codas over time. In fact, even in very early periods the four children display between 60 and $90 \%$ production of codas in stressed position. The contrast between the production of codas in stressed and unstressed positions at different ages is present to a greater or lesser degree depending on the child: Guillem for example shows a sharp difference between the two conditions (at age $2 ; 0.12$ he produces $90 \%$ of the codas in stressed position and $0 \%$ in unstressed position).

The data clearly indicate that stress plays a decisive role in licensing the presence of codas. As mentioned in section 2, the importance of the prominence factor has been previously pointed out in the literature (see Ota 2003 for Japanese, Freitas, Miguel \& Hub Faria 2001 for European Portuguese, and Lleó 2003 for Spanish). ${ }^{3}$

\subsection{Minimality effects}

Recent research has shown that children learning a number of unrelated languages exhibit a minimal word stage of development, where early words are both minimally and maximally one binary foot (e.g., Fikkert 1994 for Dutch; Demuth 2001 for Spanish, Ota 2003 for Japanese). These findings are consistent with the notion that 'unmarked' structures such as core (CV) syllables and minimal words (binary feet) are the first to emerge in children's early grammars (e.g. Fikkert 1994; Demuth \& Fee 1995; Fee 1995; Gnanadesikan 1996; Pater 1997).

This section examines the potential effect of the minimality constraint in the development of syllable structure in Catalan. Given the fact that Catalan permits monosyllabic words (and CV lexical items), we would expect that children will correctly produce $\mathrm{CV}$ targets as $\mathrm{CV}$. However, if binary feet have a privileged status in children's early grammars, there might be a tendency to augment CV inputs to form a binary foot, either through lengthening of the vowel (CVV) or through reduplication (see Ota 2003 for reports of early augmentation of subminimal words in Japanese). Close inspection of the data does not show any systematic pattern of lengthening of $\mathrm{CV}$ inputs. The following examples illustrate the pronunciation of Catalan monosyllabic CV words with no evidence of augmentation.

3. For example, in the word truncation domain, Ota (2003) concludes that in Japanese «unaccented syllables are more prone to deletion than accented ones when the target word is longer than two syllables». 


\section{Frequency of coda production (GIS)}

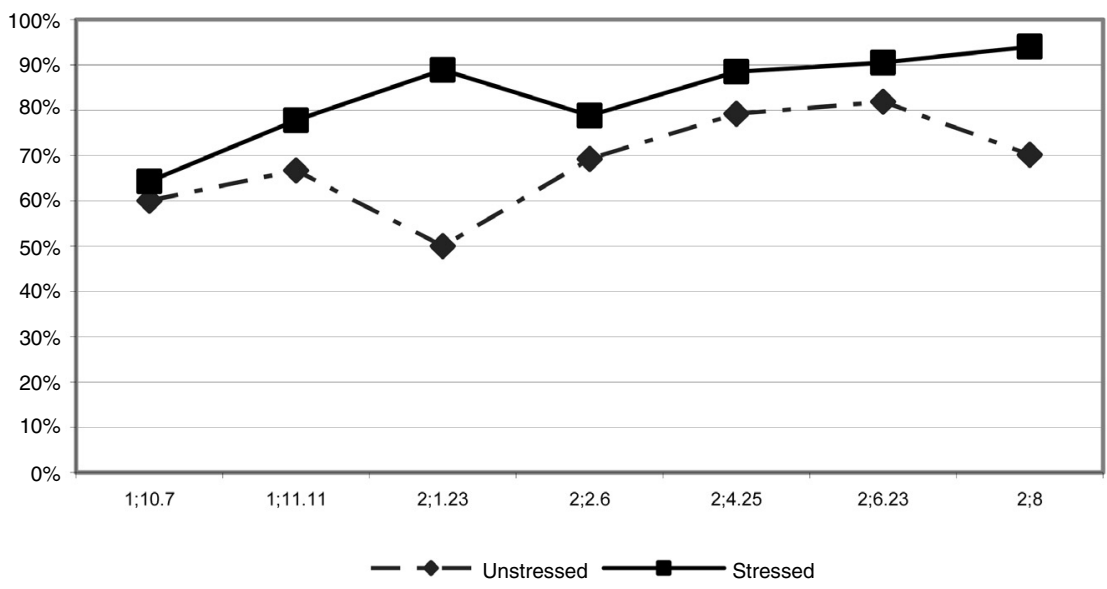

Frequency of coda production (LAU)

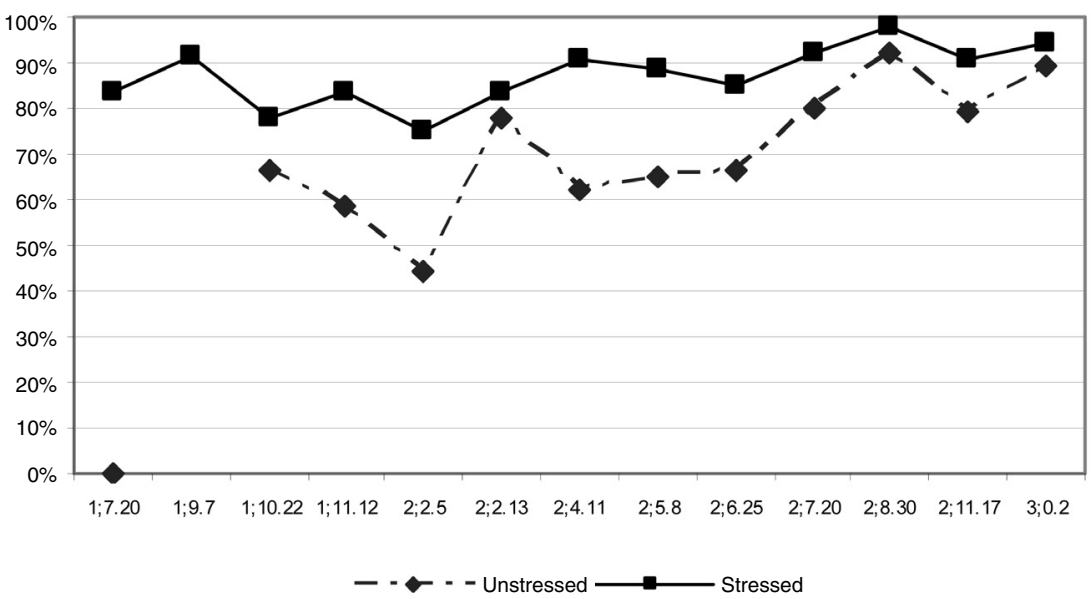

Figure 4. Frequency of coda production as a function of the stress factor (stressed vs. unstressed) for the four children. 
Frequency of coda production (GUI)

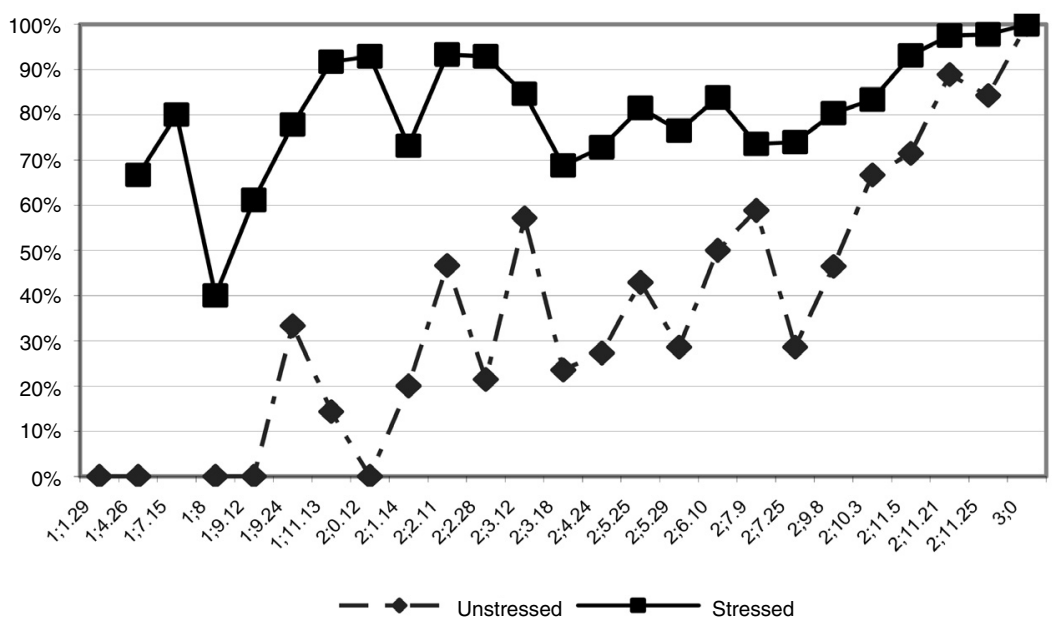

Frequency of coda production (PEP)

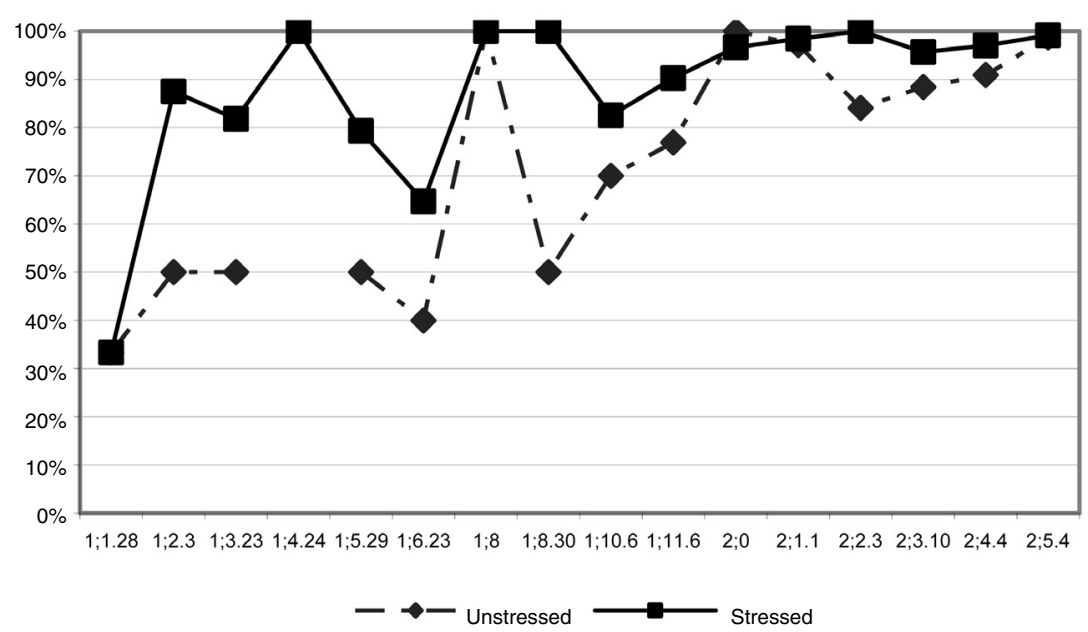

Figure 4. Frequency of coda production as a function of the stress factor (stressed vs. unstressed) for the four children (continued). 


\section{Minimality effects (GIS)}

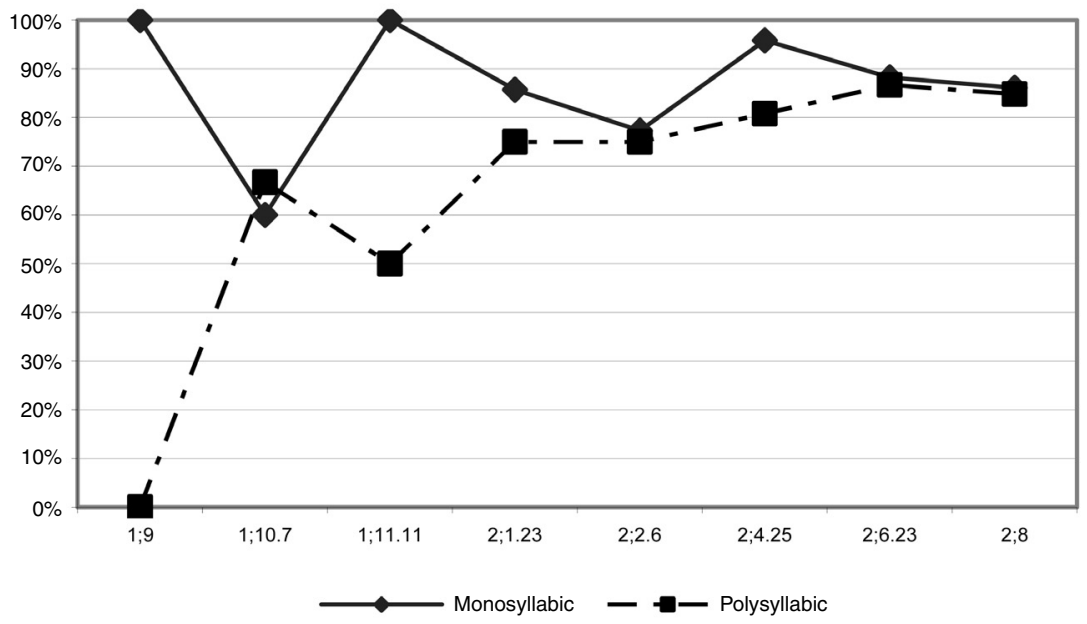

Minimality effects (LAU)

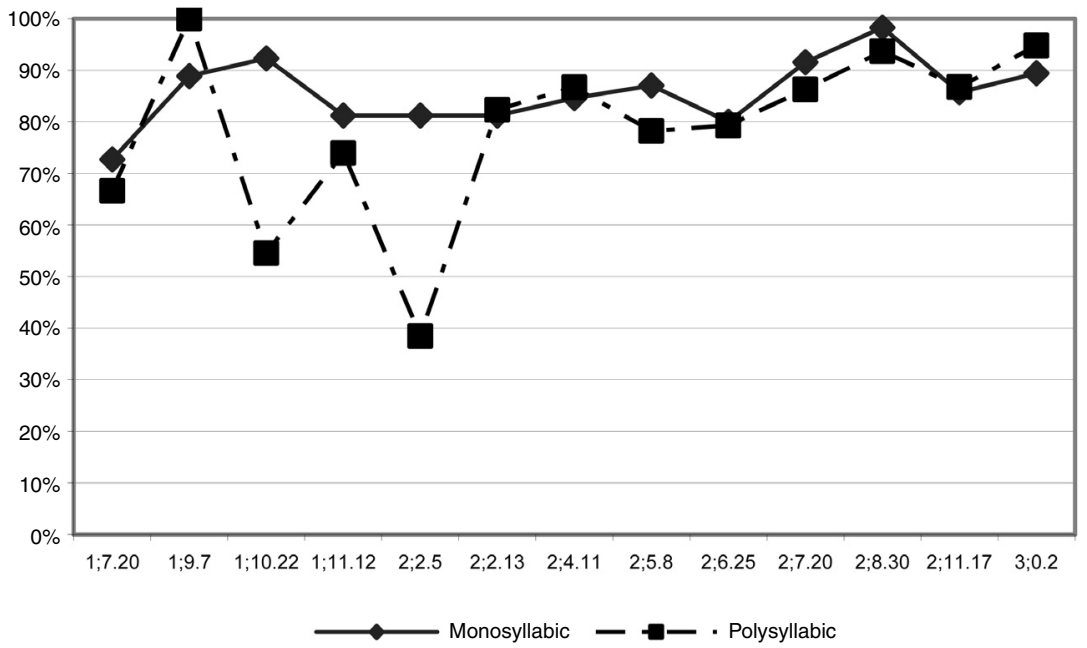

Figure 5. Frequency of coda production as a function of word-length (monosyllabic vs. polysyllabic words) for the four children. 


\section{Minimality effects (GUI)}

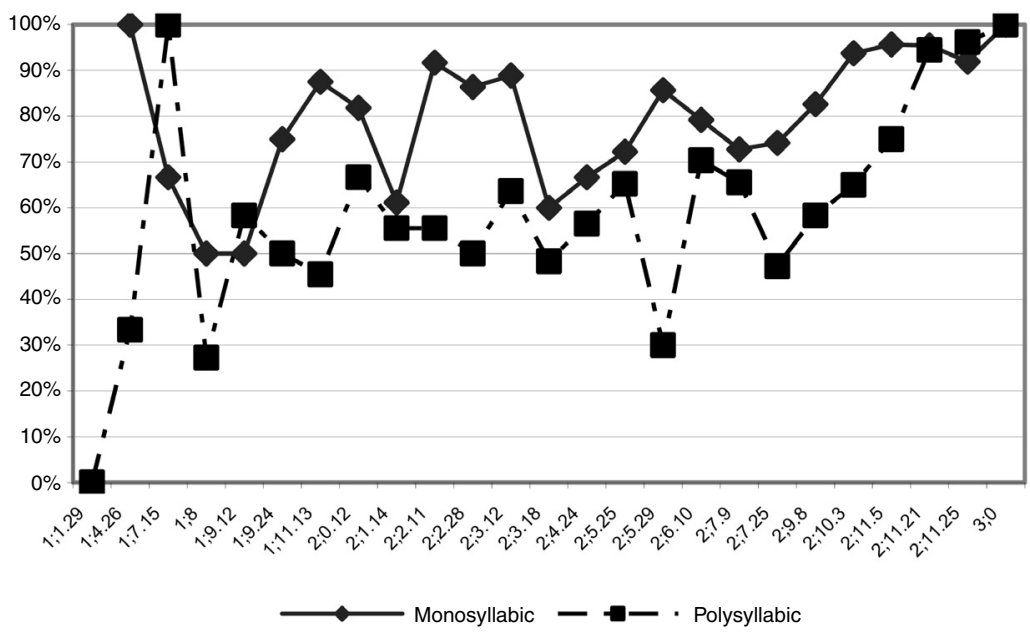

Minimality effects (PEP)

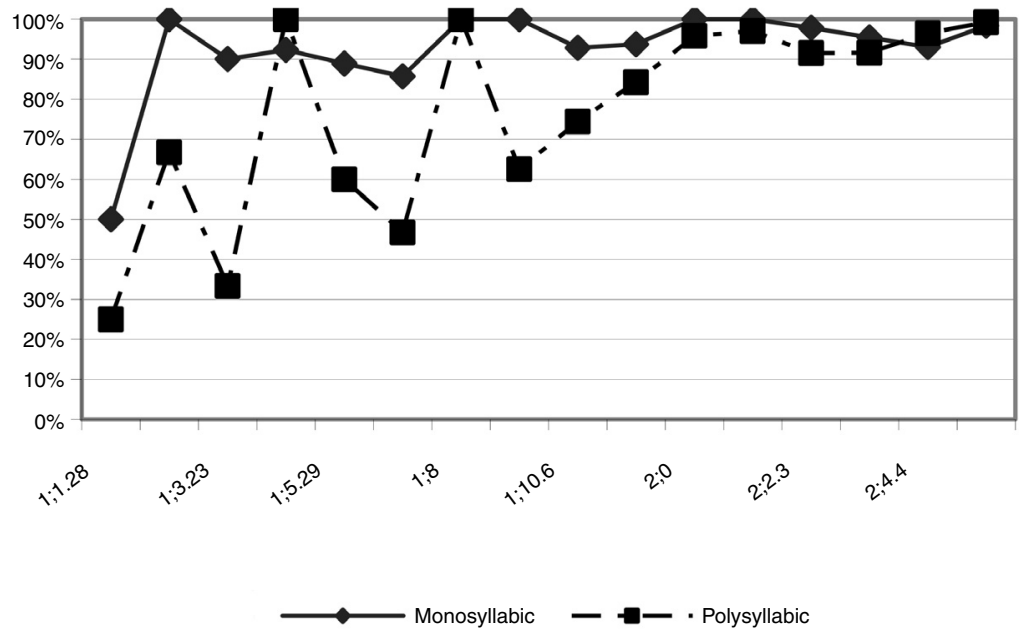

Figure 5. Frequency of coda production as a function of word-length (monosyllabic vs. polysyllabic words) for the four children (continued). 
(4) Examples CV subminimal productions

\begin{tabular}{|c|c|c|c|c|}
\hline Orth. form & Adult form & Child form & $\underline{\text { Gloss }}$ & Child \\
\hline bé & ['be] & ['me] & 'good' & Pep $1 ; 6.22$ \\
\hline$t e ́$ & ['the] & ['te] & 'take this' & Guillem $1 ; 1.29$ \\
\hline mà & ['ma] & ['ma] & 'hand' & Guillem 1;4.26 \\
\hline bo & ['bo] & ['bo] & 'good' & Laura $1 ; 7.20$ \\
\hline
\end{tabular}

On the other hand, if we take into account the potential effects of the word minimality constraint, we would expect word-final consonants in monosyllables to be acquired earlier than those in multisyllabic words because this constraint would be violated if codas in monosyllables were deleted. In a language like Catalan, where there are no long vowels phonologically, the omission of the coda of a monosyllabic word would violate the word minimality constraint. It follows that wordfinal codas in monosyllables will be acquired earlier. The 4 graphs in Figure 5 plot the percentages of coda production in monosyllabic and multisyllabic words for each child. The results indicate that the production of word-final codas in monosyllables is often higher than that in polysyllables. The asymmetry between the two contexts is clear in the first sessions: final codas in monosyllabic words are acquired earlier than in polysyllabic words (Gisela attains an $80 \%$ of coda production in monosyllables at $1 ; 9$ vs. $2 ; 4.25$ in polysyllables, Guillem at $1 ; 11.13$ in monosyllables and 2;11.21 in polysyllables, Laura at 1;9.07 vs. 2;2.13, and Pep at $1 ; 3.23$ vs. $1 ; 5.29)$.

Yet these results might be a consequence of the confounding effects of stress and word position in the data: in other words, while syllables in monosyllabic words are always stressed and word-final, this is not necessarily the case for polysyllabic words. In the following analysis, the data have been separated out and only target syllables in stressed word-final position have been selected: thus we compare the deletion of word-final codas in a word like sol 'sun' (monosyllabic) and in a polysyllabic word like cargol 'snail' (polysyllabic). The 4 plots in Figure 6 show the percentages of coda production in stressed word-final syllables as a function of word length. The 4 plots reveal that when we take stress and word position into account, no clearcut distinction between the acquisition pattern of final consonants in monosyllabic and multisyllabic words emerges: if anything, word-final codas are produced in an even more systematic way in polysyllables than in monosyllables (see the graph for Guillem, for example).

The data in this section indicate that early prosodic words in Catalan are not subject to minimality restrictions on outputs, suggesting that the minimality constraint is probably not active in quantity-insensitive languages with a sufficient exposure to $\mathrm{CV}$ subminimal words.

\subsection{Effects of within-word position}

The four plots in Figure 7 show the production of codas in word-final vs. wordmedial position for the 4 children. The graphs indicate that the production of 
word-final codas (continuous lines) is superior to that of word-medial codas (dashed lines). Pep and Laura show less than $20 \%$ word-final omissions from 1;2.3 and $1 ; 7.20$ on, respectively. Guillem's data is quite clearcut: up until 2;6 he shows a sharp contrast between word-final and word-medial codas (at this point he omits nearly an $80 \%$ of word-medial codas vs. $20 \%$ of word-final codas). In general, all children show a better performance with word-final than with word-medial consonants.

A similar contrast has been found for French (Rose 2000) and English (Goad $\&$ Brannen 2000). These authors show that final codas appear earlier than medial ones. Partly following Piggott (1999) these authors argue that word-final consonants are acquired before word-medial consonants because final consonants which are specified for place are not analyzed as codas but as onsets of syllables without nuclei. By contrast, data from two Spanish monolinguals from Lleó (2003) show that in this language there is a clear preference for medial over final codas, regardless of the fact that certain final consonants have morphological import. As Lleó (2003:271) contends, «putting all the results together, it can be claimed that in the Spanish of these two children, medial codas are produced before final codas, and stressed before unstressed.»

The contrast between Spanish vs. French and English might be attributed to differences in unmarked stress location in these languages: while French systematically places primary stress in the word-final syllable, and English contains a vast number of monosyllables, in Spanish the most general stress pattern is trochaic. Facts such as the prominence level of the syllable may be influencing early licensing of codas in medial position in Spanish. ${ }^{4}$

The four plots in Figure 8 show the production of stressed codas as a function of within-word position, that is, the graphs plot only stressed word-final vs. stressed word-medial codas (i.e., we compare the acquisition of the lateral in words such as cargol 'snail' vs. calma 'calm'). The data from the 4 children demonstrate that, even when we take the potential confounding effect of stress into account, the effect of within-word position is clear: in general, word-final codas are acquired earlier than word-medial codas.

With unstressed syllables, we also observed that word-final codas were acquired earlier than word-medial codas for the 4 children, even though the effect was smaller. We hypothesize that this word-finality effect is due to the fact that Catalan exhibits a high frequency of codas in word-final position and allows codas to be more complex in this position. This frequency acts as a facilitator of coda production in this specific context. Presumably, this would also explain the contrast found

4. Ota (2003) points out that even though crosslinguistic studies on the deletion of syllables report that word-final syllables are produced before word-medial syllables, when the prominence factor and word position are studied in combination, final syllables are more likely to be preserved only when they are unaccented (Ota 2003:151). This result reveals the methodological importance of taking into account the potential confounding effects of other factors such as prosodic prominence (pitch accent, stress) and morphological import (word-initial and word-final positions) in the licensing of coda consonants. 
Minimality effects II (GIS)

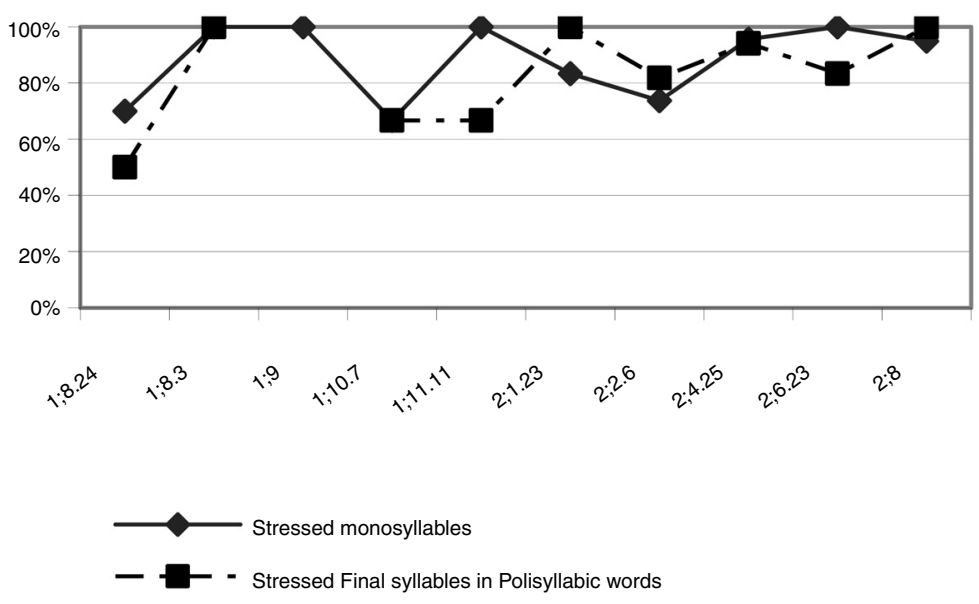

Minimality effects II (LAU)

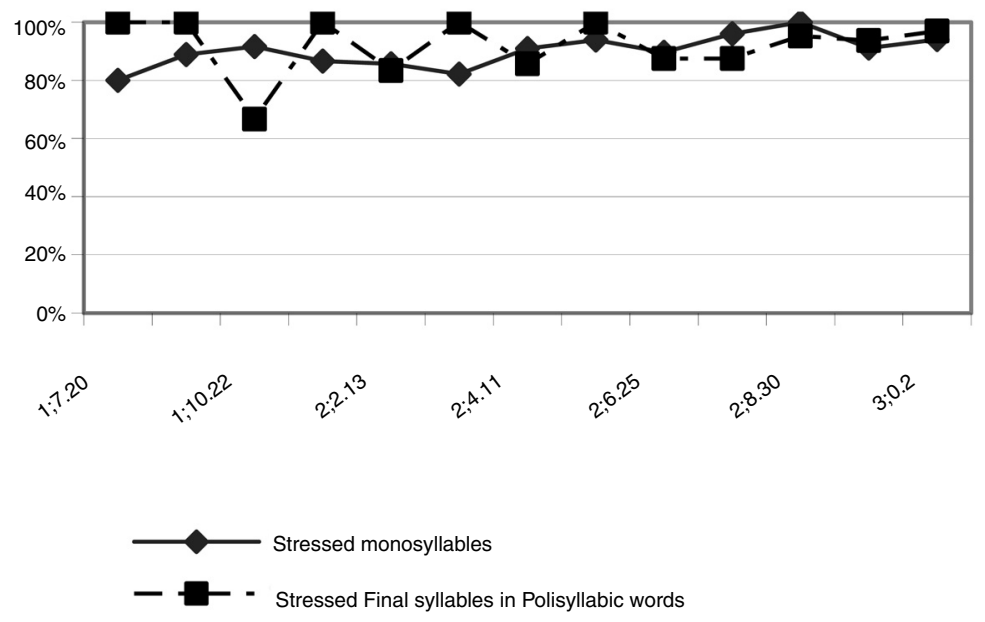

Figure 6. Frequency of coda production in stressed word-final syllables as a function of word-length (monosyllabic vs. polysyllabic words) for the four children. 


\section{Minimality effects II (GUI)}

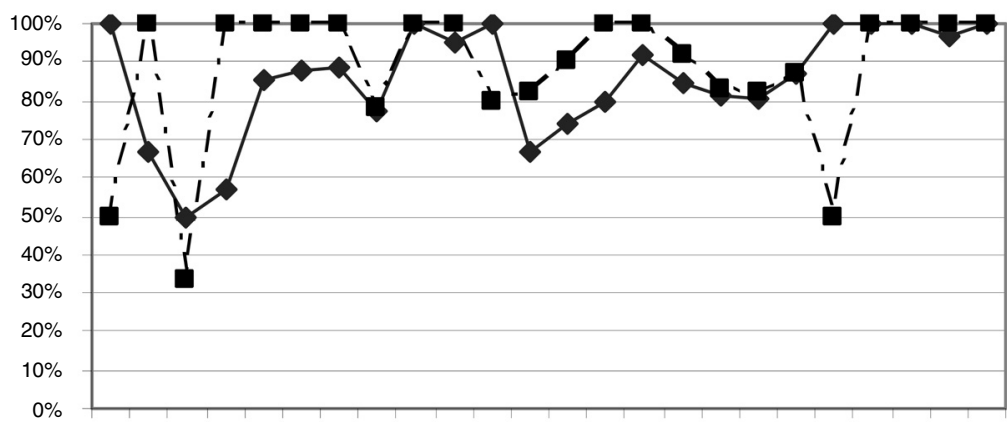

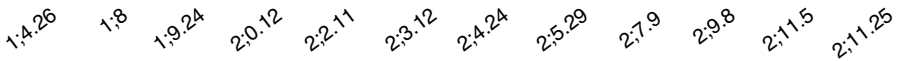

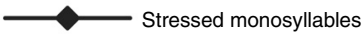

- - Stressed Final syllables in Polisyllabic words

Minimality effects II (PEP)

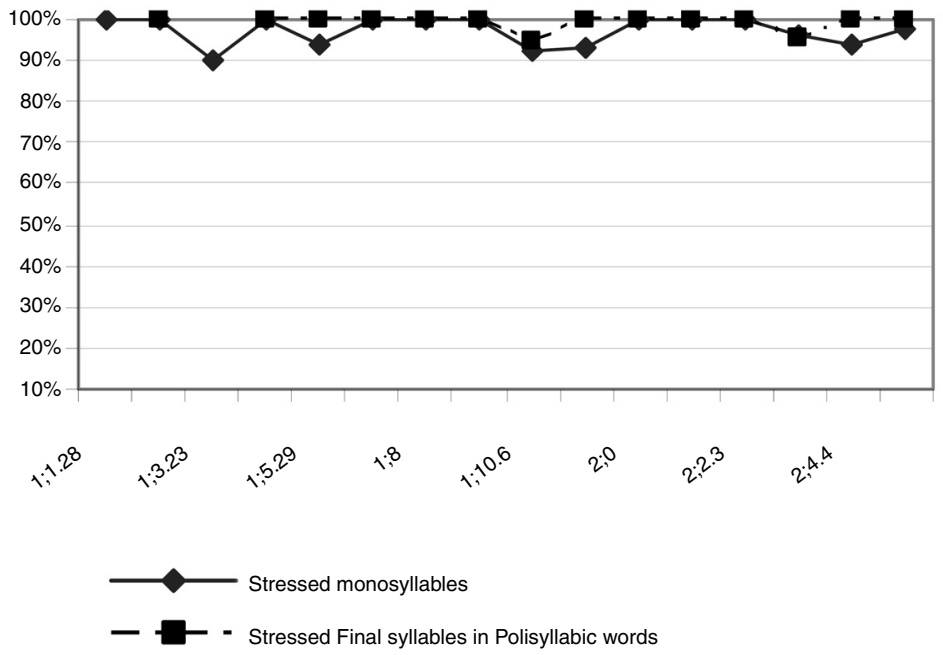

Figure 6. Frequency of coda production in stressed word-final syllables as a function of word-length (monosyllabic vs. polysyllabic words) for the four children (continued). 


\section{Effects of Within-Word Position (GIS)}

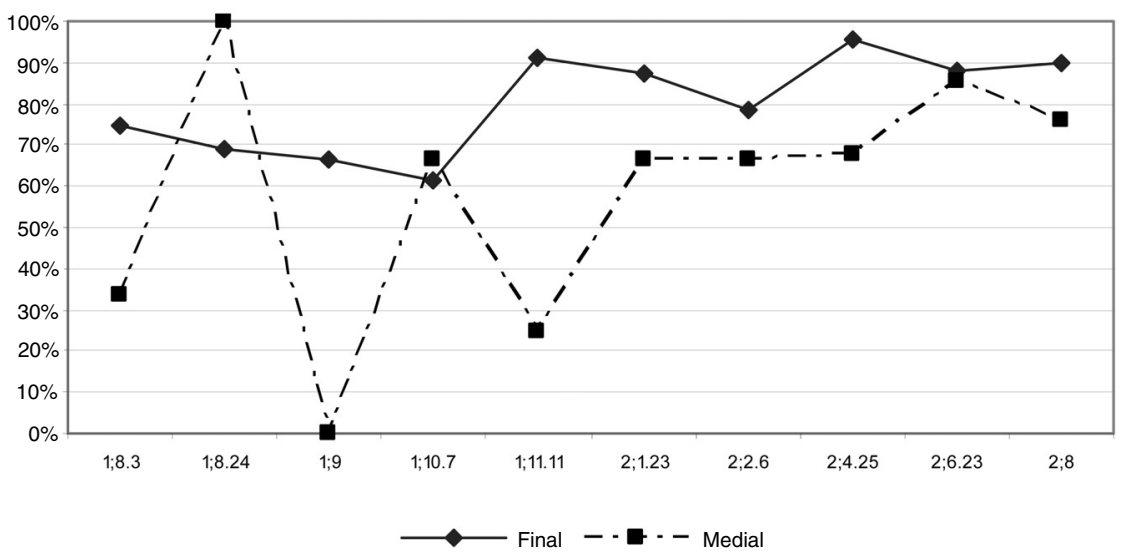

Effects of Within-Word Position (LAU)

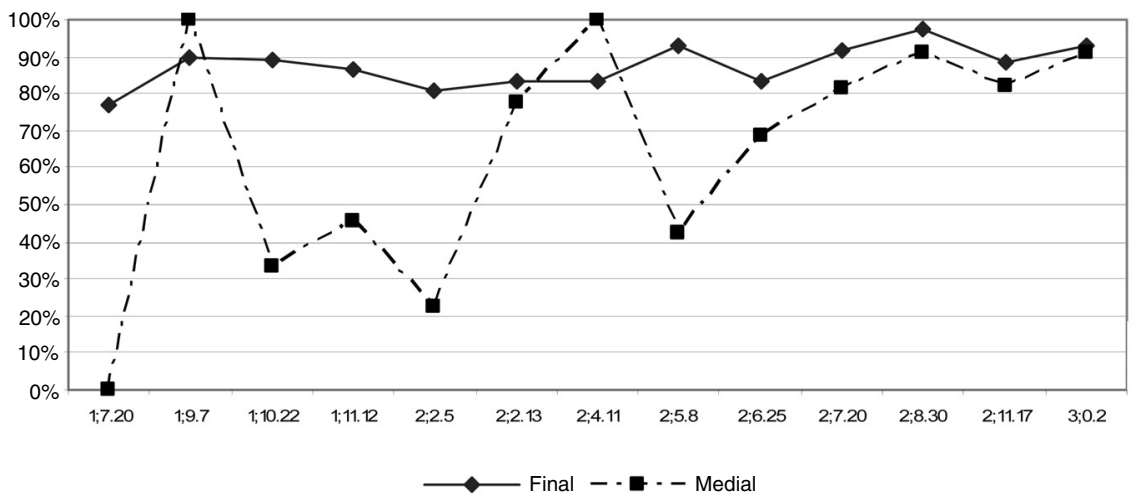

Figure 7. Frequency of coda production as a function of within-word position (word-final vs. word-medial) for the four children. 


\section{Effects of Within-Word Position (GUI)}

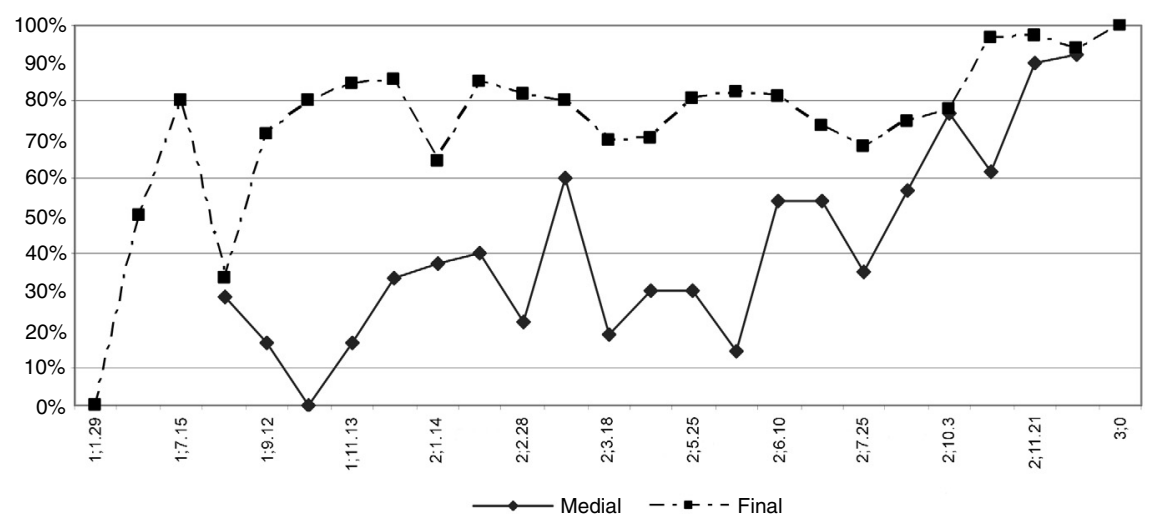

Effects of Within-Word Position (PEP)

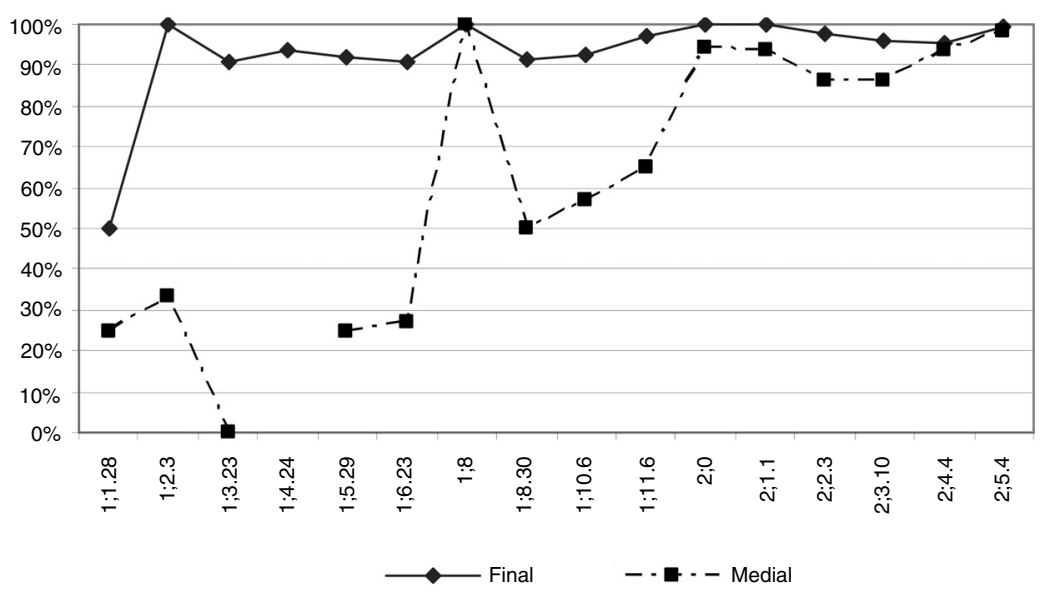

Figure 7. Frequency of coda production as a function of within-word position (word-final vs. word-medial) for the four children (continued). 


\section{Effects of Within-Word Position/Stress (GIS)}

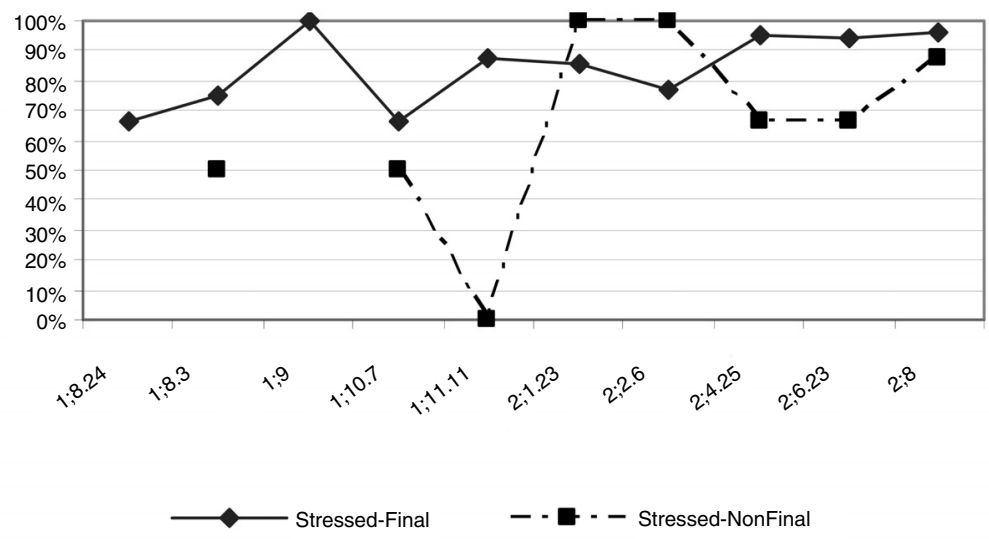

Effects of Within-Word Position/Stress (LAU)

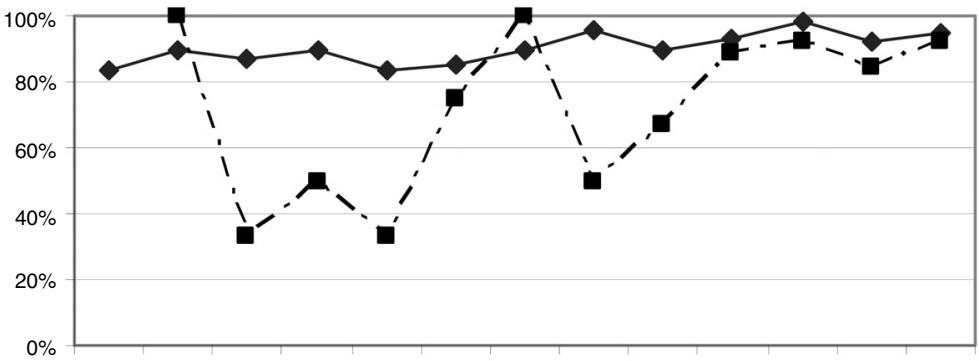

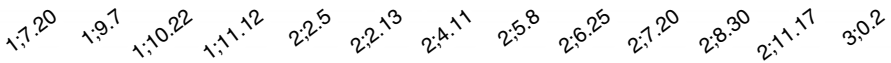

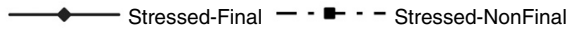

Figure 8. Frequency of coda production as a function of within-word position (word-final vs. non word-final) and stress (stressed positions) for the four children. 
Effects of Within-Word Position (GUI)

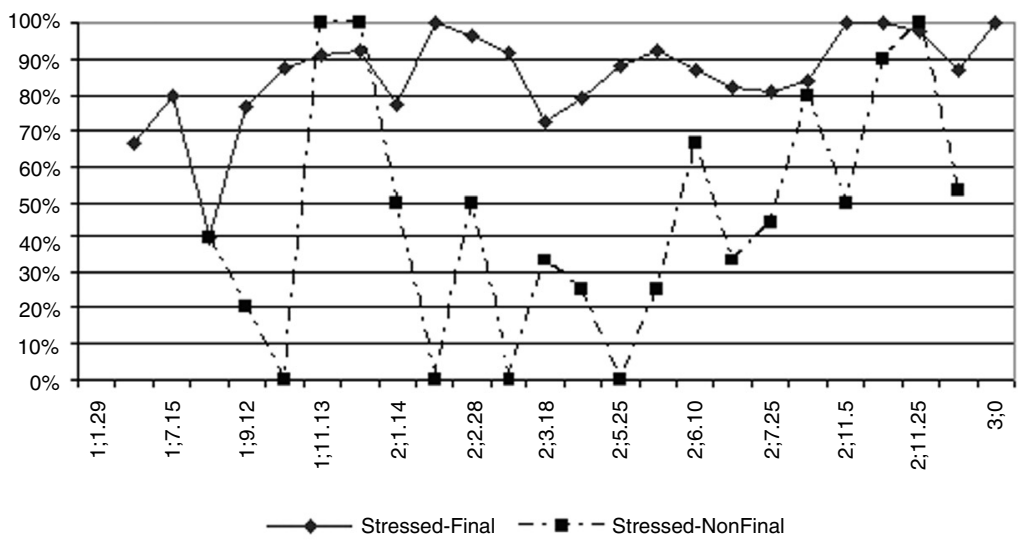

Effects of Within-Word Position (PEP)

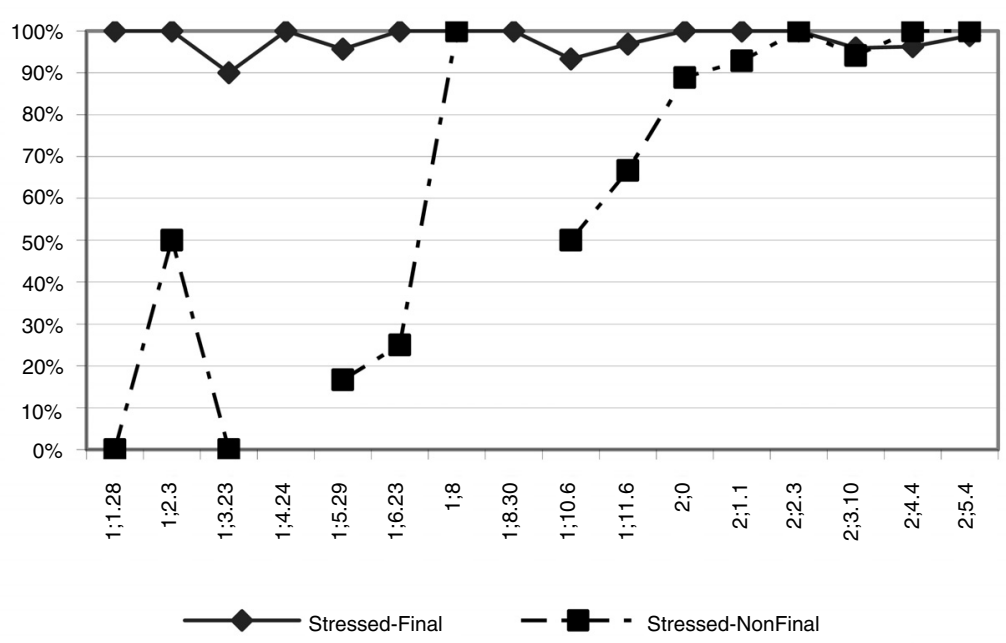

Figure 8. Frequency of coda production as a function of within-word position (word-final vs. non word-final) and stress (stressed positions) for the four children (continued). 
between Catalan and Spanish, a language where word-medial codas tend to appear earlier (see Lleó 2003, Prieto, Bosch-Baliarda \& Saceda-Ulloa 2005).

\subsection{Morphological effects}

As mentioned in section 2, Catalan codas can appear as bound morphemes or as part of bound morphemes. For example, in nominal forms, a final /-s/ can signal plurality (e.g., gat 'cat' vs. gats 'cats'). In verbal forms, a final/-s/ signals second person singular in several tense forms: parles 'you speak', parlaràs 'you will speak', parlaves 'you spoke', parlaries 'you would speak', etc. Similarly, a final /-n/ in verbal forms expresses the 3rd p.pl. in several tense forms: parlen 'they speak', parlaran 'they will speak', parlaven 'they spoke', parlarien 'they would speak', etc.

This section examines the potential effect of the morphological import of codas on their rate of acquisition. If morphological factors are important, we would expect that final codas conveying morphosyntactic information should be acquired first. According to Freitas et al, Portuguese children produce the fricative [ $\left.\int\right]$ earlier in word-final morphological position than in medial position in both noun phrases and verb phrases (see for example estes 'these' produced as ['etI $\int$ ] instead of ['e $\mathrm{tII}$ [] by Marta at 1;5.17; Freitas, Miguel \& Hub Faria (2001:54). They argue that the additional morphosyntactic information that these codas encode is speeding up the acquisition process. Thus, even though these consonants do not belong to prosodically prominent syllables (they are unstressed word-final syllables) they are nevertheless acquired earlier.

The four graphs in Figure 9 show the percentages of produced codas out of target codas classified according to their morphological status, for each child. In general, all children (Gisela, Guillem, Laura, and Pep) performed slightly better with non-morphological than with morphological codas, with individual differences. For example, Guillem seems to have a developmental course opposite to the one described by Freitas, Miguel \& Hub Faria (2001), that is, by the age of 2;5.25 he only produces $25 \%$ of the codas with grammatical content, but more than $80 \%$ of the codas with just phonological content.

The reason behind the apparent delay in the acquisition of morphological codas can be attributed to the fact that the majority of morphological codas plotted belong to unstressed syllables and are also circumscribed to a specific class of segments (even though the same situation arises in European Portuguese). As we saw in section 4.2, stress is a strong «licenser» of codas. To investigate the potential confounding effect of stress and segmental content, we selected only $-s$ codas (one of the most common morphological codas in Catalan) in unstressed position. The 3 graphs in Figure 10 plot the percentages of fricative production in unstressed position as a function of its morphological import for 3 children: ${ }^{5}$ Thus, we compare whether the $-s$ of words such as llapis 'pencil' or globus 'balloon' is acquired dif-

5. Gisela's data could not be plotted because there were very few examples of the target items in each session. 
ferently from plural markers in unstressed positions such as cases 'houses' or mares 'mothers'. The data indicate that at some points there is a slight increase in coda production in unstressed syllables with morphological function.

Summarizing, the results in this section do not lend support to the argument about the facilitating role of morphology in coda acquisition. Rather, the results advocate in favor of the idea that prosody is facilitating the acquisition of syllabic complexity, rather than morphology.

\subsection{Segmental content}

In this section, we examine the order of emergence of segments in coda position. It is generally accepted that the appearance of a given segment in a language does not legitimate its use in any structural syllabic position: in other words, segments are first available in onset position and only later generalize their use in coda position (see Freitas 2001). The order of emergence of segments seems to be languagespecific, as we find uncontrovertible contrasts across languages. For example, while in some languages obstruents emerge before sonorants — see Fikkert (1994) for Dutch and Freitas, Miguel \& Hub Faria 2001, and Freitas 2001 for European Portuguese-,${ }^{6}$ in others sonorant consonants are acquired before obstruents: for example, in Peninsular Spanish sonorant word-medial consonants appear before obstruents (Lleó 2003) ${ }^{7}$.

As shown in section 3, each coda was coded for both place and manner of articulation. The analysis was performed on the basis of manner of articulation, since it was clear from the start that we could not rely exclusively on place features for the analysis. Thus, even though coronal consonants are generally regarded to be unspecified for Place (and thus expected to be acquired earlier) the rate of acquisition of dentals and alveolars in Catalan (the plosive [t], the laterals [1], the nasal $[\mathrm{n}]$, the rhotics $[\mathrm{r}]$ and $[\mathrm{r}]$, and the fricative [s]) differs greatly. Thus, while the plosive $[\mathrm{t}]$ and the nasal $[\mathrm{n}]$ are realized practically from the start, the rhotic $[\mathrm{r}]$ and the fricative [s] are among the last to be acquired. ${ }^{8}$

First, we analyzed the percentages of coda production as a function of manner of articulation. For all children, plosives and glides are acquired practically from the start and attain $100 \%$ production quite early. The 3 plots in Figure 11 show the percentages of coda production for the rest of the consonants, namely, nasals, laterals, fricatives, and rhotics, for 3 children (Pep, Guillem, and Laura). Gisela's data was not plotted because the scarcity of the data resulted in a sketchy and uninfor-

6. Fikkert (1994) opts to represent sonorant consonants in the rhyme as part of the nucleus, and as a result they can be deleted more often when the target vowel is long.

7. For Spanish, Lleó (2003:279) reports that the majority of first acquired codas are liquids and nasals appearing in word-medial position.

8. Rhotics and fricatives are harder to acquire and they are often suppressed, even in onset position: forat [fu'at] 'hole' (Guillem 2;1.14) — see Saceda-Ulloa 2005 for examples of segmentally conditioned onset deletion in Spanish. There are also exceptions to full realization of codas in stressed position when the coda is especially hard to produce: busca ['buskə] > ['puka] '(s)he searches' (Pep 1;10.6), turista [tu'rista] > [tu'lita] 'tourist' (Pep 1;10.6). 


\section{Effects of morphology (GIS)}

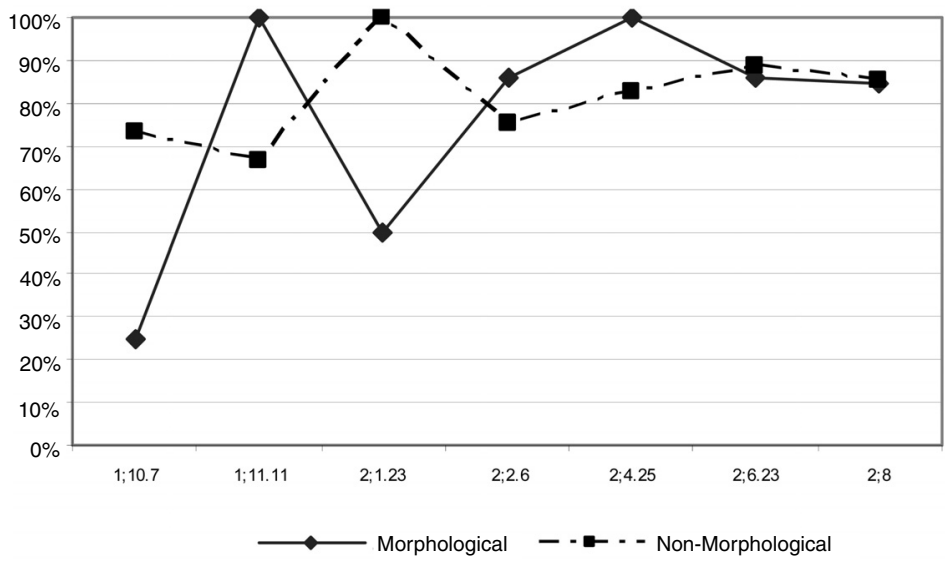

Effects of morphology (LAU)

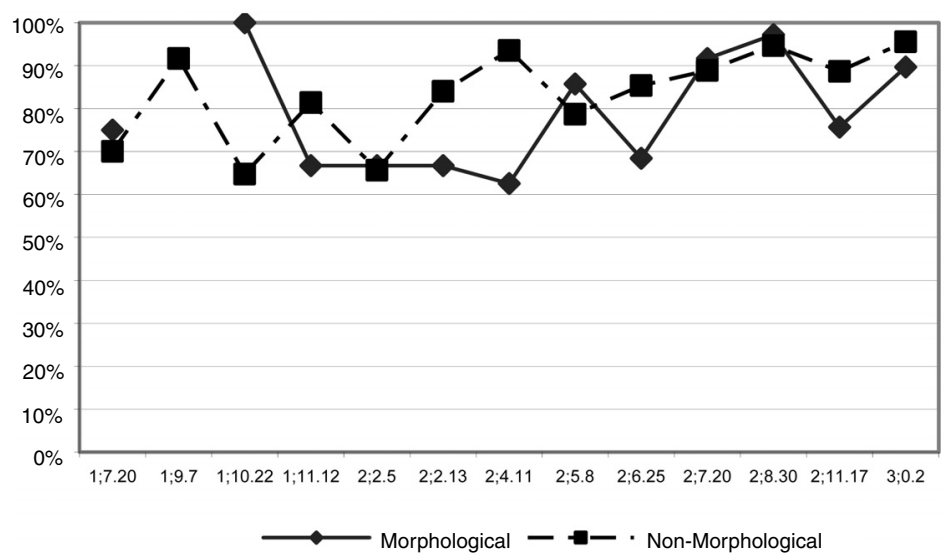

Figure 9. Frequency of coda production as a function of morphological function (morphological vs. non-morphological codas) for the four children. 


\section{Effects of morphology (GUI)}

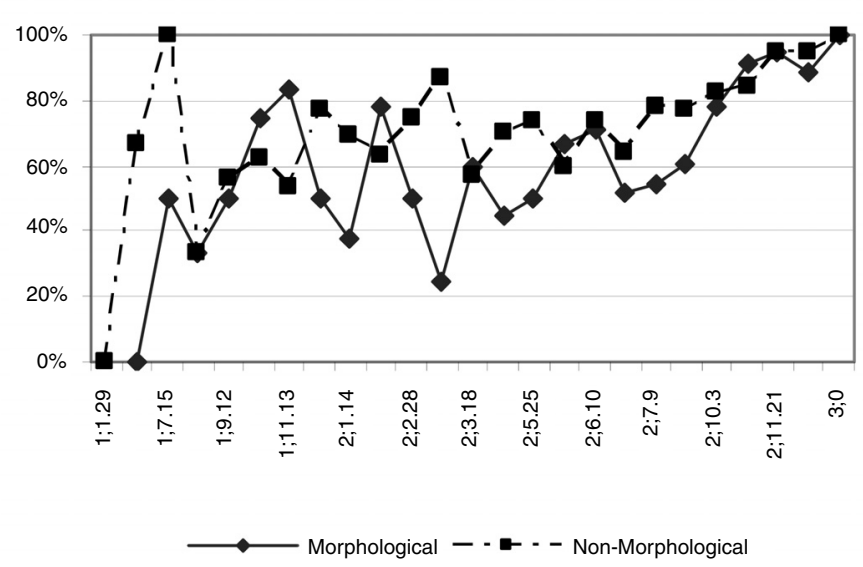

Effects of morphology (PEP)

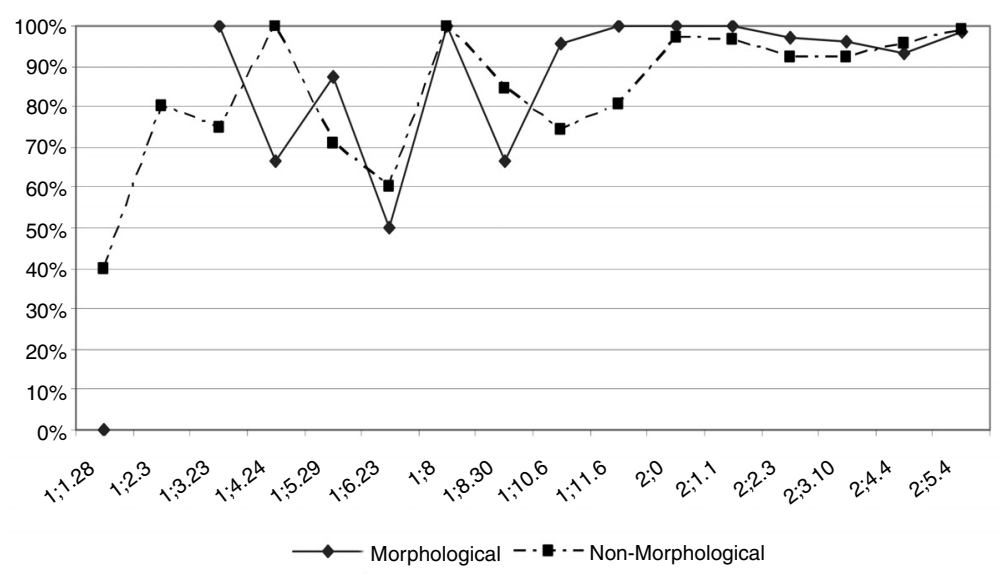

Figure 9. Frequency of coda production as a function of morphological function (morphological vs. non-morphological codas) for the four children (continued). 
Effects of morphological function on unstressed syllables (GUI)

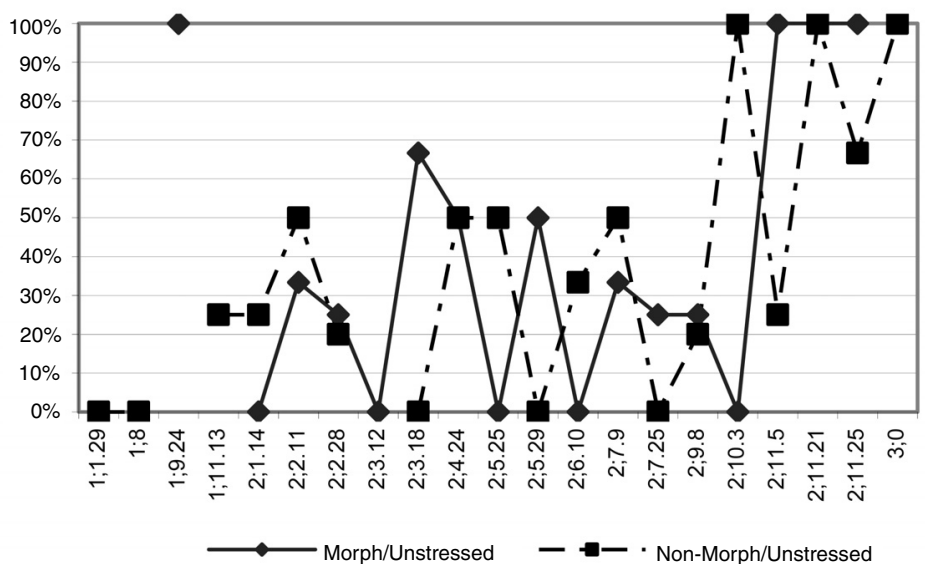

Effects of morphological function on unstressed word-final syllables (LAU)

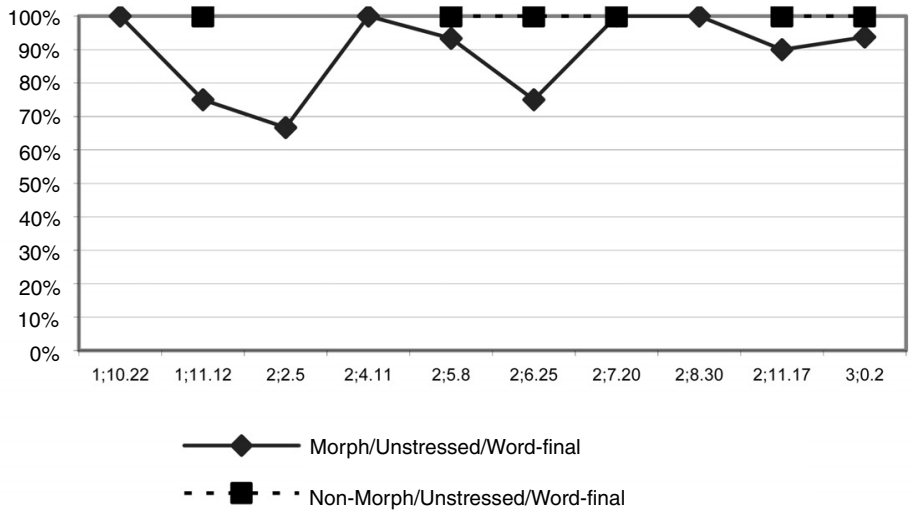

Figure 10. Frequency of coda production as a function of morphological function (morphological vs. non-morphological codas) and stress (unstressed positions) for three children. 
Effects of morphological function on unstressed syllables (PEP)

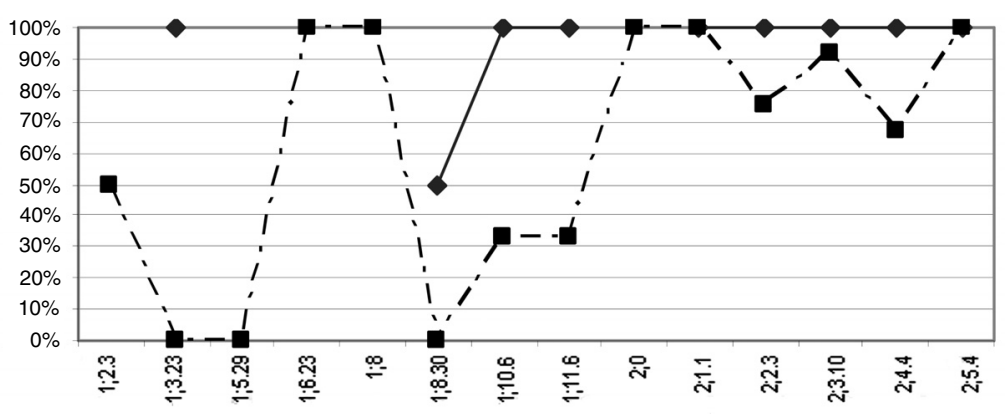

$\longrightarrow$ Morph/Unstressed - - - - Non-Morph/Unstressed

Figure 10. Frequency of coda production as a function of morphological function (morphological vs. non-morphological codas) and stress (unstressed positions) for three children (continued).

mative graph. In coda position, the children produced nasals (black triangles) before fricatives, laterals and rhotics, but we find individual variation in the acquisition of the other groups of consonants. While Laura clearly produced fricatives before rhotics and laterals, in the case of Pep and Guillem, fricative production lagged slightly behind rhotic and lateral production. Indeed, Pep's and especially Guillem's data show a poor performance in fricative pronunciation (Pep omits around 60\% of the fricatives in coda position between 1;8.30 and 2;0, and Guillem omits $60 \%$ of these segments between 2;5.25 and 2;10.3). We also find individual variation in the acquisition of laterals and rhotics: while Pep and Laura show a better performance with laterals than with rhotics, this pattern is not so clearcut in Guillem's case.

Summarizing, our Catalan data show that plosives, nasals and glides are the first consonants to be acquired by all children. The results in this section provide evidence that segmental content has to be taken into account in coda acquisition, and that obstruent and sonorant consonants cannot be considered as homogeneous groups. Thus, we find a distinction within the sonorant group: while nasals and glides are among the first segments to be acquired by the child, laterals and rhotics are among the last.

Finally, the acquisition of complex codas in our data also provides evidence that the type of consonant involved is crucial in its acquisition pattern. We could not perform quantitative and longitudinal analyses on complex codas because their rate of appearance was not very high. An analysis of the error patterns found reveals that by far one of the complex codas that was systematically simplified by the four 


\section{Effects of manner of articulation (GIS)}

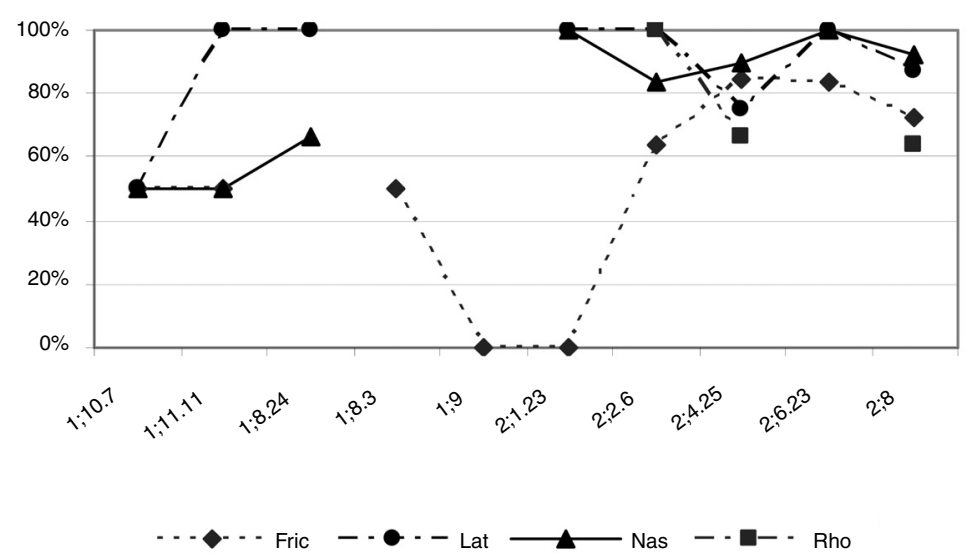

Effects of manner of articulation (GUI)

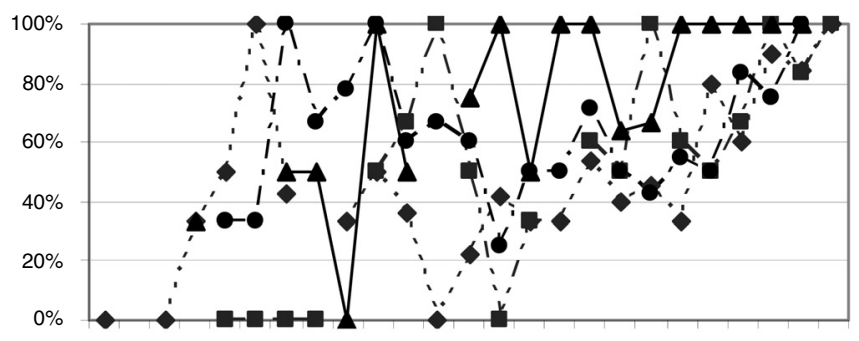

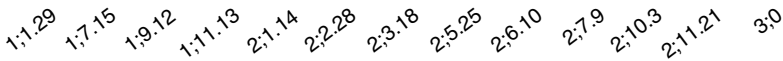

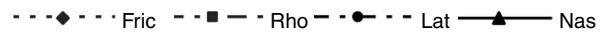

Figure 11. Frequency of coda production as a function of manner of articulation (nasals, laterals, fricatives, and rhotics) for the four children. 


\section{Effects of manner of articulation (LAU)}

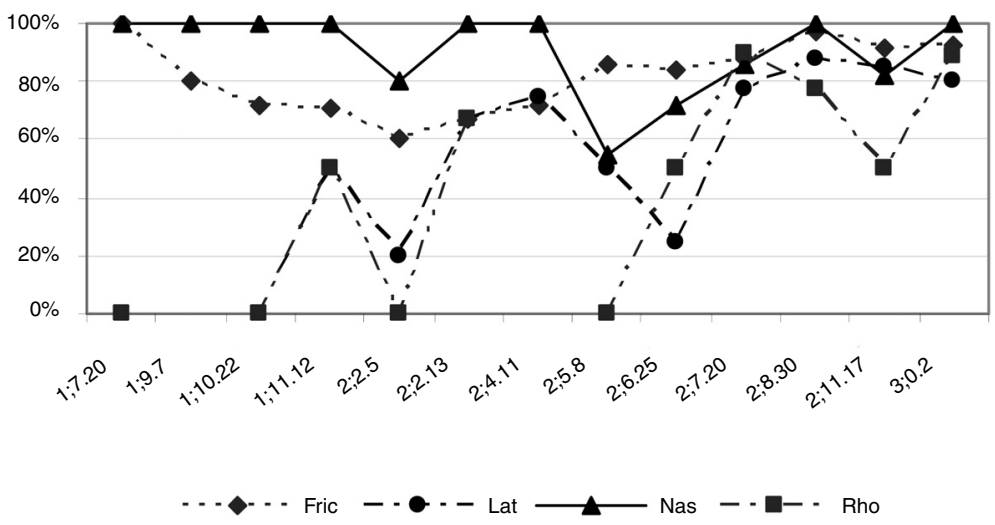

Figure 11. Frequency of coda production as a function of manner of articulation (nasals, laterals, fricatives, and rhotics) for the four children (continued).

children was $-r d$ or $-r t$ into $>t$, as the examples in (5) and (6) show. The simplification pattern found follows the so-called «sonority pattern», a pattern whereby children typically reduce clusters to the least sonorous segment (in this case, C2).

(5) Examples of $-\mathrm{rC}$ simplification

\begin{tabular}{|c|c|c|c|c|}
\hline$\underline{\text { Orth. form }}$ & $\underline{\text { Adult form }}$ & $\underline{\text { Child form }}$ & $\underline{\text { Gloss }}$ & $\underline{\text { Child }}$ \\
\hline mort & ['mort] & ['mot] & 'dead.ms' & Pep 1;11.6 \\
\hline verd & ['bert] & ['bet] & 'green' & Gisela $2 ; 4.5$ \\
\hline surt & ['surt] & ['tut] & '(s)he leaves' & Guillem 1;9.12 \\
\hline Marc & ['mark] & ['tat] & 'Mark' & Guillem 1;9.12 \\
\hline verd & ['bert] & ['bet] & 'green' & Guillem 2;3.18 \\
\hline verd & ['bert] & ['bet] & 'green' & Laura $1 ; 11.12$ \\
\hline
\end{tabular}

(6) Examples of complex coda production

\begin{tabular}{|c|c|c|c|c|}
\hline Orth. form & $\underline{\text { Adult form }}$ & $\underline{\text { Child form }}$ & $\underline{\text { Gloss }}$ & Child \\
\hline cèrvols & ['serßuls] & ['teßuls] & 'deer' & Pep 1;11.6 \\
\hline peixets & [pə'ets] & [po'tets] & 'fish.dim' & Pep $1 ; 11.6$ \\
\hline cargols & [kər' yols] & [ka' yols] & 'snails' & Pep 1;11.6 \\
\hline lleons & [Кว'ons] & [Кว'ons] & 'lions' & Pep 1;11.6 \\
\hline vols & ['bols] & ['bols] & 'you want' & Gisela $2 ; 4.5$ \\
\hline
\end{tabular}




\begin{tabular}{|c|c|c|c|c|}
\hline Orth. form & $\underline{\text { Adult form }}$ & Child form & $\underline{\text { Gloss }}$ & $\underline{\text { Child }}$ \\
\hline tinc & ['tipk] & ['tijk] & 'I have' & Gisela $2 ; 4.5$ \\
\hline patins & [рә & & 'roller blades' & Gisela $2 ; 4.5$ \\
\hline pantalons & lons] & [pə & 'trou & Gisela $2 ; 4.5$ \\
\hline cims & ['sims] & ['sir & 'mountain tops' & Guillem 2;3.18 \\
\hline tots & ['tot & ['to & 'all' & Guillem 2;3.18 \\
\hline Faust & [fa & [fa & 'prop & $2 ; 3.18$ \\
\hline dolç & ['dols] & ['dols] & 'sweet.ms' & Guillem $2 ; 3.18$ \\
\hline
\end{tabular}

\section{Conclusion}

The developmental data from four Catalan-speaking children has revealed that codas appear with the first word productions. This pattern contrasts with that of languages like Spanish or Japanese where coda consonants in the input are less frequent (see Lleó 2003 and Ota 2003) and is more similar to English and German (Bernhardt \& Stemberger 1998 and Grijzenhout \& Joppen 1998 respectively). Thus our findings suggest that language learners are sensitive to a degree of exposure to the relevant structure in the input: that is, a certain amount of the key structure can facilitate early acquisition of this particular structure.

This paper presents empirical evidence in favor of the decisive role of prosodic prominence in the early development of coda consonants: it is clear that stressed syllables make their coda available before unstressed syllables, independently of factors such as within-word position or morphological import. The privileged status of stressed syllables as heads of feet is also clear in patterns of truncation in early phonology: clearly, stress «protects» syllables from deletion. In general, stress prominence and word position determine whether a syllable is more or less prominent from a prosodic point of view. Another important result of the article is the significant word-finality effect found in the data: for the four children, word-final codas are acquired earlier than word-medial codas, regardless of stress. These two results clearly indicate that the development of syllable structure in Catalan, and specifically the gradual emergence of codas, is facilitated by the presence of heads and/or edges of higher prosodic domains.

The behavior of Catalan thus provides evidence for the importance of the distributional frequency of prosodic structures in the ambient language, as codas are acquired earlier in the contexts where they appear most frequently (stressed syllables, word-final positions). This result contrasts with that of Spanish, where word-medial codas are acquired earlier than those in word-final position (see Lleó 2003, Saceda-Ulloa 2005, Prieto, Bosch-Baliarda \& Saceda-Ulloa 2005). A recent comparison of coda acquisition in Catalan and in Spanish has shown that children are extremely sensitive to the frequency distribution of codas in the language: the fact that Catalan-speaking children acquire codas in word-final position earlier than Spanish children can be attributed to the fact that words with final codas are far more frequent in this language (Prieto, Bosch-Baliarda \& Saceda-Ulloa 2005). 
Finally, the Catalan data presented in this article also contribute to the discussion about the potential facilitating effect of morphology in phonological acquisition. While Freitas et al. (2001) find evidence for an early emergence of plural markers (expressed as word-final coda fricative [-f]) in European Portuguese, Lleó (2003, this volume) reports late acquisition of plural markers (word-final coda fricative [-s]). In Catalan, morphological codas are not acquired earlier than the other codas. The Catalan data lend support to the idea that the acquisition of syllabic structure is highly constrained by prosody. In other words, prosody, not morphology, seems to be the intermediate domain which facilitates the acquisition of syllabic complexity.

\section{References}

Bernhardt, Barbara H.; Stemberger, Joseph P. (1998). Handbook of Phonological Development from the Perspective of Constraint-Based Nonlinear Phonology. New York: Academic Press.

Bonet, Eulàlia; Lloret, Maria-Rosa (1998). Fonologia catalana. Barcelona: Ariel.

Demuth, Katherine (2001). «Prosodic constraints on morphological development». In: Weissenborn, Jürgen; Höhle, Barbara (eds.). Approaches to Bootstrapping: Phonological, syntactic and neurophysiological aspects of early language acquisition, vol. 1. Amsterdam: John Benjamins, pp. 3-21.

Demuth, Katherine; Fee, Jane E. (1995). «Minimal words in early phonological development». Ms. Brown University and Dalhousie University.

Fee, Jane E. (1995). «Segments and syllables in early language acquisition». In: Archibald, J. (ed.). Phonological Acquisition and Phonological Theory. Hillsdale, New Jersey: Lawrence Erlbaum Associates, pp. 43-61.

Fikkert, Paula (1994). On the Acquisition of Prosodic Structure. The Hague: Holland Academic Graphics.

Freitas, Maria João (2001). «Syllabic constituency and segmental emergence: Evidence from the acquisition of European Portuguese». In: Almgren, Margareta; Barreña, Andoni, Ezeizabarrena, María-José; Idiazabal, Itziar; MacWhinney, Brian (eds.). Research on Child Language Acquisition, vol. 2. Somerville: Cascadilla Press, pp. 45-57.

Freitas, Maria João; Miguel, Matilde; Hub Faria, Isabel (2001). «Interaction between prosody and morphosyntax: Plurals within codas in the acquisition of European Portuguese». In: Weissenborn, Jürgen; Höhle, Barbara (eds.). Approaches to Bootstrapping: Phonological, Lexical, Syntactic and Neurophysiological Aspects of Early Language Acquisition, vol. 2. Amsterdam: John Benjamins, pp. 45-57.

Gnanadesikan, Amalia E. (1995). «Markedness and faithfulness constraints in child phonology». Rutgers optimality archive. ROA-67. Ms.

Goad, Heather; Brannen, Kathleen (2003). «Phonetic evidence for phonological structure in syllabification». In: van de Weijer, Jeroen; van Heuven, Vincent; van der Hulst, Harry (eds). The phonological spectrum, vol. 2. Amsterdam: John Benjamins, pp. 3-30.

Grijzenhout, Janet; Joppen, Sandra (1998). First Steps in the Acquisition of German Phonology: A Case Study. Theorie des Lexikons. Arbeiten des sonderforschungsbereichs 282 , nr. 110 . 
Harris, James W. (1983). Syllable Structure and Stress in Spanish. The MIT Press: Cambridge, Massachusetts.

Levelt, Clara C.; Schiller, Niels O.; Levelt, Willem J. (1999/2000). «The acquisition of syllable types». Language Acquisition 8: 237-264.

Lleó, Conxita (2003). «Prosodic licensing of codas in the acquisition of Spanish», Probus 15: 257-281.

Lleó, Conxita; Kuchenbrandt, Imme; Kehoe, Margaret; Trujillo, Cristina (2003). «Syllable final consonants in Spanish and German monolingual and bilingual acquisition». In: Müller, Natascha (ed.). (In)Vulnerable Domains in Multilingualism. Amsterdam: John Benjamins, pp. 191-220.

MacWhinney, Brian; Snow, C. (1985). «The Child Language Data Exchange System». Journal of Child Language 12: 271-296.

Ota, Mitsuhiko (2003). The Development of Prosodic Structure in Early Words. Amsterdam: John Benjamins.

Pater, Joe (1997). «Minimal violation and phonological development». Language Acquisition 6.3: 201-253.

Piggott, Glyne L. (1999). «At the right edge of words». The Linguistic Review 16: 143-185.

Pye, Clifton; Ingram, David; List, Helen (1987). «A comparison of initial consonant acquisition in English and Quiche». In K.E. Nelson \& A. van Kleek (eds.). Children's Language. Erlbaum: Hillsdale.

Prieto, Pilar (2006). «The relevance of metrical information in early prosodic word acquisition: A comparison of Catalan and Spanish». Language and Speech (special issue on the Crosslinguistic Perspectives on the Development of Prosodic Words, ed. by Katherine Demuth) 49 (2), 233-261.

Prieto, Pilar; Bosch-Baliarda, Marta; Saceda-Ulloa, Marta (2005). «The development of codas in Catalan and Spanish: frequency effects in specific contexts». Xth International Congress for the Study of Child Language. Berlin, July 25-29, 2005.

Saceda-Ulloa, Marta (2005). Adquisición prosódica en español peninsular: la sílaba y la palabra prosódica. MA Thesis. Universitat Autònoma de Barcelona. http://seneca.uab.es/ggt/tesis.htm.

Seguí, J.; Dupoux, E; Mehler, J. (1990). «The role of the syllable in speech segmentation, phoneme identification and lexical access». In: G. Altmann (ed). Cognitive Models of Speech Processing. Cambridge: MIT Press.

Stites, Jessica; Demuth, Katherine; Kirk, Cecilia (2004). «Markedness versus frequency effects in coda acquisition». In Alejna Brugos, Linnea Micciulla, \& Christine E. Smith (eds.). Proceedings of the 28th Annual Boston University Conference on Language Development, pp. 565-576.

Roark, Brian; Demuth, Katherine (2000). «Prosodic constraints and the learner's environment: A corpus study». In: Catherine Howell, S.; Fish, Sarah A.; Keith-Lucas, Thea (eds.). Proceedings of the 24th Annual Boston University Conference on Language Development, Somerville, MA: Cascadilla Press, pp. 597-608.

Rose, Yvan (2000), Headedness and prosodic licensing in the L1 acquisition of phonology. McGill University, Montréal: Doctoral Dissertation. 